\title{
Key factors of Carbon footprint in the UK food supply chains: A new perspective of life cycle assessment
}

\begin{tabular}{|r|l|}
\hline Journal: & International Journal of Operations and Production Management \\
\hline Manuscript ID & IJOPM-06-2019-0478.R1 \\
\hline Manuscript Type: & Research Paper \\
\hline Keywords: & Food supply chain, CO2 emission, Sales and distribution \\
\hline \multicolumn{2}{|l}{} \\
\end{tabular}




\title{
Key factors of Carbon footprint in the UK food supply chains: A new perspective of life cycle assessment
}

\begin{abstract}
Purpose - The purpose of this paper is to empirically identify key factors of UK food supply chains (SCs) that significantly contribute to $\mathrm{CO}_{2}$ emissions $\left(\mathrm{CO}_{2} \mathrm{e}\right)$ taking into account the life cycle assessment (LCA). The UK food supply chain includes imports from other countries.

Design/Methodology Approach - This research develops a conceptual framework from extant literature. Secondary data obtained from ONS and FAOSTAT covering from 1990 to 2014 are analysed using Multilinear Regression (MLR) and Stochastic Frontier Analysis (SFA) to identify the factors relating to $\mathrm{CO}_{2}$ emissions significance, and the efficient contributions that are being made to their reduction in the UK food supply chains.

Findings - The study results suggest that Transportation and Sales/Distribution are the two key factors of $\mathrm{CO}_{2}$ emissions in UK food supply chains. This is confirmed by two multivariate methods, MLR and SFA. MLR results show that transportation increases $\mathrm{UK} \mathrm{CO}_{2}$ emissions by 10 tonnes of $\mathrm{CO}_{2}$ emissions from one tonne of fruits and vegetables imports from overseas to the UK. Sales and Distribution reduces the UK $\mathrm{CO}_{2}$ emissions by 1.3 tonnes of $\mathrm{CO}_{2}$ emissions due to improved, technological operation activities in the UK. In addition, the SFA results confirm that the key factors are sufficient to predict an increase or decrease in $\mathrm{CO}_{2}$ emissions in the UK food supply chains.

Research limitations/implications - This study has focused on the LCA of the UK food supply chain from limited data. Future studies should consider Sustainability Impact Assessment of the UK food supply chain, identifying the social, economic, regulatory and environmental impacts of the food supply chain using a redefined LCA (all-inclusive assessment) tool.

Practical implications - This research suggests that food supply chain professionals should improve efficiency, e.g., the use of solar energy and biogas, and also integrate low-carbon policies and practices in food supply chain operations. Furthermore, governments should encourage policies such as mobility management programmes, urban redevelopment and privatisation to enhance better transportation systems and infrastructure to continuously reduce $\mathrm{CO} 2 \mathrm{e}$ from the food trade.

Originality - Although logistics play a major role in $\mathrm{CO}_{2}$ emissions, all logistics $\mathrm{CO}_{2}$ emissions for other countries are not included in the ONS data. This research reveals some important insights into the UK food supply chains. Logistics and other food supply chain processes of importing countries significantly contribute to $\mathrm{CO}_{2}$ emissions which are yet to be considered in the UK food SCs.
\end{abstract}

Keywords Food Supply Chain, $\mathrm{CO}_{2}$ emissions, Sales and Distribution, low carbon operations

Paper type Research paper

\section{Introduction}

Forty per cent of UK fresh food supply is reliant on imports from European countries (e.g., France, Spain, Germany, the Netherlands and Ireland). Other nations - namely India, Ghana, Chile, South Africa and China are also supplying varieties of fresh food to the UK. About 25 nations are responsible for $90 \%$ of the total UK fresh food supply (Defra, 2012). In all these, the UK Food Standards Agency plays a vital role in supporting food security and food quality. Nevertheless, the importation of UK fresh food generates a significant amount of $\mathrm{CO}_{2}$ emissions $\left(\mathrm{CO}_{2} \mathrm{e}\right)$, contributing to the consumption-based emissions of the UK (Michalský and Hooda, 2015). Although the carbon footprint associated with UK consumption reduced in 2016 by $6 \%$ between 2015 to 2016, Defra estimated UK's consumption-based emissions as $784 \mathrm{MT} \mathrm{CO}_{2}$ equivalent (Defra, 2017a). Despite the significant decrease from 601.3 $\mathrm{MT} \mathrm{CO}_{2} \mathrm{e}$ (in 1990) to $398 \mathrm{MT} \mathrm{CO}_{2} \mathrm{e}$ (in 2016), the UK still generates more $\mathrm{CO}_{2} \mathrm{e}$ compared to other countries in Europe. Several studies (Davis and Caldeira, 2010; Barrett et al., 2013; de Ruiter et al., 2016) have also reflected on the size of the UK's carbon footprint, attributing to the imports from Europe, China and the rest of the world. Davis and Caldeira (2010) pointed out that the UK is the third highest net importer of $\mathrm{CO}_{2} \mathrm{e}$ following the USA and Japan at an amount of 253 MT $\mathrm{CO}_{2}$ e per year. Barrett et al.'s (2013) research showed that the UK's territorial $\mathrm{CO}_{2} \mathrm{e}$ are much less compared to consumption-based $\mathrm{CO}_{2} \mathrm{e}$. The differential growth between territorial $\mathrm{CO}_{2} \mathrm{e}$ and consumption-based $\mathrm{CO}_{2} \mathrm{e}$ is higher than that of most of the leading industrial economies in the world, including China, the USA, Germany, Japan and Canada. The consumption-based $\mathrm{CO}_{2}$ e accounting provides an absolute picture of a country's 
progress in both national and regional $\mathrm{CO}_{2} \mathrm{e}$ mitigation. Moreover, de Ruiter et al. (2016) stress that $\mathrm{CO}_{2} \mathrm{e}$ associated with the UK food supply chains (FSC) are widely generated from overseas operations.

Following the significant sustainability impacts (e.g., land use $\mathrm{CO} 2 \mathrm{e}, \mathrm{CO} 2 \mathrm{e}$ from transportation, food waste and energy use for storage) associated with fresh food revealed by literature, this study focuses on fruits and vegetables import by the UK from eight countries representing four continents. Furthermore, fruits and vegetables exports to developed countries - e.g., the UK, the USA, Japan and Canada - are rapidly expanding (Garnett, 2011), making it a fascinating area of study. Although meat and dairy contribute significant $\mathrm{CO}_{2} \mathrm{e}$ in the UK FSC (Scarborough et al., 2014; Bates et al., 2019), fruits and vegetables imports are consistently increasing at a high rate compared to different food categories (UK Trade Experimental Statistics, 2018). Table I shows greenhouse gas emissions (mainly $\mathrm{CO}_{2} \mathrm{e}$ ) associated with food categories production and typical western diet. In contribution to that, Defra is working with all food industry players, the third sector, consumers and international organisations to secure a sustainable food system that reduces $\mathrm{CO}_{2} \mathrm{e}$ associated with the food supply. Efforts put in place include encouraging the use of local food, and education and research on sustainable FSC (Sustainable Development Commission, 2012). Nonetheless, more pragmatic policies, measures and approaches are needed to reduce $\mathrm{CO}_{2} \mathrm{e}$ associated with the UK's FSC other than voluntary measures.

Table I. GHG emissions (in $\mathrm{CO} 2 \mathrm{e}$ ) associated with food categories production and typical western diet

\begin{tabular}{|c|c|c|c|}
\hline \multicolumn{2}{|c|}{$\begin{array}{l}\text { Greenhouse gas (GHG) emissions for food } \\
\text { categories production (weighted) in the } \\
\text { UK including import from EU and outside } \\
\text { EU }\end{array}$} & \multicolumn{2}{|c|}{$\begin{array}{l}\text { Contribution of different food categories to } \\
\text { diet-related GHG emissions (CO2e) }\end{array}$} \\
\hline Food Category & $\begin{array}{l}\text { GHG emissions } \\
\text { (kgCO2e/kg) }\end{array}$ & Food Category & $\begin{array}{l}\text { Per cent of GHG } \\
\text { emissions (CO2e) in } \\
\text { typical western diet }\end{array}$ \\
\hline Meat & 35.9 & $\begin{array}{l}\text { Meat, Beans, Fish, } \\
\text { and Other non-dairy } \\
\text { proteins }\end{array}$ & 57 \\
\hline Fruits and Vegetables & 1.6 & Fruits and Vegetables & 11 \\
\hline Milk & 1.8 & Milk and Diary & 14 \\
\hline Poultry Meat & 5.4 & $\begin{array}{l}\text { Bread, Potato, Pasta, } \\
\text { Rice and Other starchy } \\
\text { foods }\end{array}$ & 6 \\
\hline Rice & 3.9 & $\begin{array}{l}\text { Food and Drinks } \\
\text { (High in Sugar and/or } \\
\text { Fat) }\end{array}$ & 5 \\
\hline Fish & 5.4 & $\begin{array}{l}\text { Other Miscellaneous } \\
\text { Foods e.g., Alcohol, } \\
\text { Sources and Hot } \\
\text { drinks }\end{array}$ & 7 \\
\hline Tea & 1.9 & & \\
\hline Wheat/Oats & 1.0 & & \\
\hline Sugar & 0.1 & & \\
\hline
\end{tabular}

Some studies on $\mathrm{CO}_{2} \mathrm{e}$ associated with the UK FSC (Marriott, 2005; Garnett 2006; Saunders and Hayes, 2007; Garnett, 20011; Porter et al., 2018) reveal limited attention to Life Cycle Assessment (LCA). There is a lack of research that captures a broad assessment of the UK FSC, considering $\mathrm{CO}_{2} \mathrm{e}$ associated with all stages of the FSC activities. The FSC involves the farming process and its inputs, through to manufacturing, 
distribution, preservation, retailing, food preparation and waste disposal. However, there is limited literature on the UK FSC considering $\mathrm{CO}_{2} \mathrm{e}$ estimation which includes all activities of FSC from outside the UK.

Therefore, the purpose of this paper is to determine key factors of the UK food supply chain that significantly contribute to $\mathrm{CO}_{2} \mathrm{e}$, considering the life cycle assessment (LCA). The LCA enables the capture of environmental and other related impacts (mainly $\mathrm{CO}_{2} \mathrm{e}$ ) throughout the life cycle of a food item. While existing LCA studies (e.g., Pullman and Wikoff, 2017) published in renowned journals such as the IJOPM focus on determining $\mathrm{CO}_{2} \mathrm{e}$ of a few stages of the life cycle or the domestic supply chain, this paper suggests all-inclusive assessment. In other words, we re-define LCA to consider the entire supply chain starting from overseas sources. Understanding LCA study from this perspective provides a more robust approach when estimating $\mathrm{CO}_{2} \mathrm{e}$ generated in the supply chain and a more holistic idea of how to practically reduce the carbon footprints. In this case, all activities of the FSC involving carbon use are considered in the LCA. Among others, the activities include land use, synthetic fertiliser use, organic soil farming, on-farm transportation, overseas storage, packaging, road transport, air transport, delivery, storage, distribution, and waste. To enhance implementation of sustainable policies and measures within specific areas of the supply chains, we group all the activities into areas of operations and supply chain management activities which we refer to as the "key factors". Thus, Growers' Field, Inland Logistics, Transportation and Sales and Distribution were considered. We further study whether the factors are efficient in using their resources to show a relationship between the UK FSC and $\mathrm{CO}_{2} \mathrm{e}$, through re-defined LCA. In this article we use re-defined LCA to represent activities of FSC outside the UK that have $\mathrm{CO}_{2} \mathrm{e}$. This is particularly important to measure carbon footprint for the food supplies exported to the UK.

The study therefore addresses the following research questions:

\section{RQ1. What are the key factors that significantly contribute to $\mathrm{CO}_{2}$ emissions of UK food supply chains?}

RQ2. What are the measures that policymakers and business managers can employ to reduce $\mathrm{CO}_{2}$ emissions associated with UK food supply chains?

Drawing from existing studies (Pretty et al., 2005; Smith et al., 2007), a conceptual framework is developed to enable identification of all the stages of FSC from outside (exporting countries) to the UK. Secondary data have been obtained from the Office for National Statistics (ONS), and the Food and Agriculture Organisation of the United Nations Statistics (FAOSTAT). They are ranked through empirical analysis using Multilinear Regression (MLR) and Stochastic Frontier Analysis (SFA). This paper contributes to extant literature on the UK FSC by capturing and including LCA data of countries that export food to the UK to give a holistic view of the UK FSC. First, we undertake an empirical study identifying the key factors of the UK FSC, taking into account $\mathrm{CO}_{2} \mathrm{e}$ generated throughout the FSC which is cross-checked regarding data reliability by the use of two multivariate methods (MLR and SFA). This study provides pragmatic measures and approaches that policymakers and business managers can explore to mitigate consumption-based $\mathrm{CO}_{2} \mathrm{e}$, more specifically in the fresh FSC.

The rest of the paper is organised as follows. The next section provides a literature review on the UK FSC focused on fruit and vegetables followed by a review of life cycle assessment, carbon footprint and mitigation measures. Next, in section three, we explain the research methodology including the conceptual framework, data collection and the model. This is followed by an analysis of the empirical results in section four and discussions including managerial implications in section five. Finally, we provide a conclusion, key contributions and research limitations, and offer suggestions for future research.

\section{Literature}

\subsection{FSC (FSC): UK Fruits and Vegetables}

Food supply chains produce Greenhouse gases (GHGs), mainly $\mathrm{CO}_{2} \mathrm{e}$, throughout all the stages of the life cycle from farming processes through to warehousing, production, storage, distribution, retailing, consumption and disposal of waste (Garnett, 2006). Many studies have examined the $\mathrm{CO}_{2} \mathrm{e}$ generated throughout a FSC; e.g., Garnett (2006) Garnett (2011), López et al. (2015), Porter et al. (2018) and Vitali et al. (2018). There is significant evidence in the literature on attempts made in reducing the $\mathrm{CO}_{2} \mathrm{e}$ associated with FSC (Gadema and Oglethorpe, 2011; Oglethorpe and Heron, 2013; Ramanathan et al., 2014). Ramanathan et al. (2014) suggest use of collaboration to reduce $\mathrm{CO}_{2} \mathrm{e}$; Oglethorpe and Heron (2013) and Hendry et al. (2019) advocate local FSC; and Gadema and Oglethorpe (2011) focus on carbon labelling and carbon footprint.

Modern FSC entails many stages and mostly spans multiple nations and continents (Schoenherr et al., 2015). In that regard, examining the food supply of a country needs a holistic perspective, taking into account where the food is grown and what stages are involved through to the final consumer. Nevertheless, food miles 
- the distance from farm to the fork of the final consumer (Moxham, 2004; Pullman and Wikoff, 2017) - have played a role as a relative $\mathrm{CO}_{2} \mathrm{e}$ indicator. Conversely, Coley et al. (2011) question the use of food miles as a driving force for communicating the value of $\mathrm{CO}_{2} \mathrm{e}$. Likewise, early research by Watkiss (2005) argued that a single indicator based on food miles (total food distance) is an inadequate indicator. So, estimating $\mathrm{CO}_{2} \mathrm{e}$ associated with the entire FSC needs to be assessed through a wider lens, taking into consideration all stages of the FSC in communicating the "true" value of $\mathrm{CO} 2 \mathrm{e}$ arising across every activity that contributing to producing and consuming the food item. This will enable tailoring appropriate measures to tackle that stage or factor within the FSC while stakeholders make wiser decisions.

The UK's FSC emits between $152 \mathrm{Mt} \mathrm{CO}_{2}$ and $159 \mathrm{Mt} \mathrm{CO}_{2}$ (Audsley et al., 2010), which makes up 20\% of the overall UK total emission. Further, in 2014, UK FSC CO 2 e increased and was responsible for 176 million tonnes of $\mathrm{CO}_{2}$ e (Tassou et al., 2014). Bates et al. (2019) claim that food consumption generates $30 \%$ of the environmental impacts of households, while the Committee on Climate Change (2019) estimated UK's consumption related $\mathrm{CO}_{2} \mathrm{e}$ as $784 \mathrm{MtCO} \mathrm{e}$. This is a significant contribution to the UK's total $\mathrm{CO}_{2} \mathrm{e}$ and calls for urgent attention. Food is imported from across the globe and the UK shift from manufacturing to services is one reason for the drift in $\mathrm{CO}_{2} \mathrm{e}$ in the UK FSC (Baiocchi and Minx, 2010). Among the food imported by the $\mathrm{UK}$, fruit and vegetables are the leading food import in terms of trade value and $\mathrm{CO}_{2} \mathrm{e}$. Fruits and vegetables have overtaken food items such as sugar, coffee, fish cereal, meats and beverages (Defra, 2017b). Fresh fruit and vegetables are supplied by various local and global producers to help maintain price stability and resilience of food supply (Parson, 2013), while also complementing domestic production.

Fruits and vegetables imported by the UK were estimated at $£ 5.2$ billion in 2015 as against $£ 199$ million for export with the EU countries (namely the Netherlands, Germany, France and Spain) supplying $40 \%$ of the fruit and vegetables. The remaining $60 \%$ are supplied by Africa, Asia and the rest of the world (AHDB, 2016). Fruit and vegetables produced in the UK is less than 10\% (Defra, 2017b), therefore, large volumes of fresh fruits and vegetables are imported into the UK regularly, leading production of significant amount of $\mathrm{CO}_{2} \mathrm{e}$ yearly. Previous studies reveal that the UK fruits and vegetables supply is responsible for about $2.5 \%$ of the UK GHG emissions (Garnett, 2006). However, there is still a gap between theoretical emphasis and empirical studies in estimation of $\mathrm{CO}_{2} \mathrm{e}$ of the UK fruits and vegetables supply chain. Also, to appropriately determine $\mathrm{CO}_{2} \mathrm{e}$ generated within the UK fruits and vegetables supply chains, new research needs to take account of the LCA of the food supply chain. Studies that have examined the activities of the UK FSC and its related $\mathrm{CO}_{2} \mathrm{e}$ implications are summarised in Table 1.

\subsection{Life Cycle Assessment (LCA), Carbon Footprint, Policies and Measures for $\mathrm{CO}_{2}$ e Mitigation}

Life cycle assessment (LCA) is commonly referred to as environmental accounting of all aspects of resources' use and environmental effects associated with the system from cradle to grave (Curran, 1996; 2008; Finnveden et al., 2009; Krishna et al., 2017). Curran (2008) clearly highlights that LCA provides a holistic view of the environmental aspects related to a product over the start of its life cycle, ranging from raw materials' extraction, production distribution through to the use, reuse and disposal of the product. This enables assessment of the environmental aspect of food product in four stages: (i) defining the big aspect of the product life cycle, (ii) description of the activities and energy flows within the product systems, (iii) detailing the product for impact assessment, and (iv) critical review and interpreting the life cycle of the product (Krishna et al., 2017). Assessment of the environmental effects of food can consist of five relevant indicators: GHG emissions, the use of land, acidification, freshwater withdrawals weighted by scarcity of local water, and eutrophication (Poore and Nemecek, 2018). However, measuring carbon footprint is often considered as one of the LCA indicators. Also, this methodology is widely accepted by practitioners and academics (International Trade Centre, 2012; Jensen, 2012).

Carbon footprint enables the estimation of greenhouse gas (GHG) emissions (mainly $\mathrm{CO}_{2} \mathrm{e}$ ) of the entire FSC -from the extraction or preparation of raw materials through all stages of production, storage, transportation, distributions, usage of food item and disposal (International Trade Centre, 2012; Röös et al., 2013). Therefore, based on the evidence from the literature, this study uses LCA as a method of estimating the carbon footprint of the entire FSC, starting from the exporting country (outside the UK). The main limitation of using LCA is truncation of the system boundary of LCA (Lenzen, 2000), its complexity, and its timeconsuming nature (Caro, 2019). Nonetheless, this study has invested time, attention and limited LCA in the capturing of $\mathrm{CO} 2 \mathrm{e}$ associated with all stages of the FSC, considering all hotspots and big aspects of the food life cycle. Using this LCA method will help capture $\mathrm{CO}_{2} \mathrm{e}$ generated at every stage in the FSC.

A considerable number of studies have examined the FSC using LCA (Mogensen et al., 2009; McCarthy et al., 2015; Noya et al., 2018). However, these are limited to examining $\mathrm{CO}_{2} \mathrm{e}$ of one stage or a few stages of the FSC. For example, Mogensen et al. (2009) estimated $\mathrm{CO}_{2} \mathrm{e}$ associated with transporting vegetables. Further, the study estimated the environmental impacts (e.g., acidification, eutrophication and land use) associated vegetables and other food stuffs. Nevertheless, extant literature focuses on the UK fruits and vegetables using LCA, while consideration of all stages of overseas FSC processes is limited. There is not much evidence of 
literature that considers a wider scope of using LCA as a carbon footprint of the entire of FSC, taking into account all activities of exporting countries. Research by Marriott (2005) and Garnett (2006) considered a few aspects of carbon footprint, but not all stages of the FSC. Such limitation is also seen in relevant literature such as Schahczenski and Hill (2009) who focus on organic agriculture, Cadarso et al. (2010) who focus on sea transport and Greene and Plotkin (2011) who focus on freight transportation. Lack of statistical data is mentioned as the cause for limited contribution from academics (Garnett, 2006). Recently, de Ruiter et al. (2016) argued that complexity of the UK FSC could be the reason for this. Nevertheless, the amount of $\mathrm{CO}_{2} \mathrm{e}$ associated with the UK FSC - e.g., transportation - is alarming (Defra, 2013) and demands the attention of all stakeholders (policymakers, business managers, researchers, FSC professionals and consumers).

Some useful policies and measures have been suggested in the literature, e.g., Brand and Preston (2010) advocate cap-and-trade and carbon price, Sundarakani et al. (2010) suggest green purchase and supply, Barrett et al. (2013) present policy-oriented research, and Ramanathan et al. (2014) discuss carbon footprint and carbon labelling. Very recently, the work of de Sousa Jabbour et al. (2019) suggested that low-carbon operations can contribute to a more sustainable society. The low-carbon operations entail a number of aspects, e.g., design of product, production and processes, transportation, packaging and distribution to reduce energy consumption and $\mathrm{CO}_{2}$ emissions (Du et al., 2015). It is believed that the empirical research on reducing $\mathrm{CO}_{2} \mathrm{e}$ in the UK FSC will provide coherent and robust findings to enable stakeholders to provide more realistic policies and measures towards the stages (factors) involved in the FSC that generate significant amounts of CO2e. Studies that have examined the activities of the UK FSC and its related $\mathrm{CO}_{2} \mathrm{e}$ implications are summarised in Table II.

Table II. Studies on activities of UK food supply chains and its related CO2e implications.

\begin{tabular}{ll}
\hline Study & Findings \\
\hline Jones (2002) & $\begin{array}{l}\mathrm{CO}_{2} \mathrm{e} \text { associated with supply of fresh food to the UK consumers } \\
\text { transported by trucks or planes is greater than rail. }\end{array}$ \\
\hline Marriott (2005) & $\begin{array}{l}\text { Significant portion of } \mathrm{CO}_{2} \mathrm{e} \text { is associated with fresh food import from } \\
\text { EU and non-EU countries. Majority of this } \mathrm{CO}_{2} \mathrm{e} \text { is caused by food } \\
\text { transport. }\end{array}$ \\
\hline Garnett (2006) & $\mathrm{CO}_{2} \mathrm{e}$ are generated throughout the life cycle hotspots of FSC. The \\
hotspots include transportation, storage and waste.
\end{tabular}

Saunders et al. (2006) $\quad \mathrm{CO}_{2}$ e per tonne of apples produced in the UK are higher than in the New Zealand due to higher use of energy.

McKinnon and Piecyk (2012) Significant amount of $\mathrm{CO}_{2} \mathrm{e}$ produced from transport operations.

Hulthén and Gadde (2009) Modified distribution facilities (e.g., trucks and distribution centres)

efficiently utilised can reduce fuel consumption and $\mathrm{CO}_{2} \mathrm{e}$.

Audsley et al. (2010) A significant proportion of $\mathrm{CO}_{2}$ e (101 $\mathrm{Mt} \mathrm{CO}_{2}$-equivalent emissions) from global land use change attributable to the UK FSC.

Garnett (2011) $\quad$ FSC produces $\mathrm{CO}_{2}$-equivalent emissions at all stages in its life cycle, starting from the farming process and its inputs, through to manufacturing, refrigeration, distribution, retailing, food preparation and waste disposal. Evidence shows that in addition to technological mitigation, there is need to shift patterns of consumption.

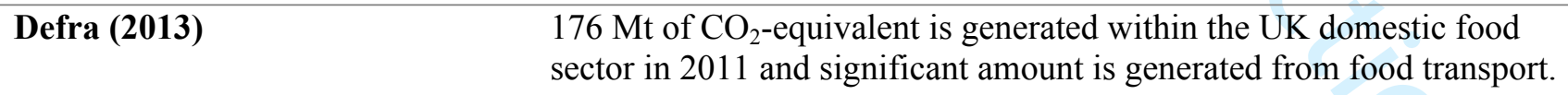

Mangalassery et al. (2014) Adopting zero tillage systems such as crop residue cover play significant role in reducing $\mathrm{CO} 2 \mathrm{e}$.

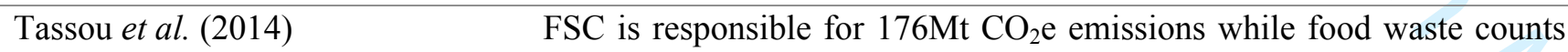
for $15 \mathrm{Mt} \mathrm{CO} 2$ equivalent emissions. $\mathrm{CO}_{2} \mathrm{e}$ are generated throughout the FSC, e.g., agriculture, manufacturing, domestic operations, storage, transport, retail and catering.

de Ruiter et al. (2016) The UK is increasingly reliant on outsourcing countries and the $\mathrm{CO}_{2} \mathrm{e}$ associated with the FSC is increasingly generated from overseas operations. 


\section{Methodology and conceptualisation}

Based on a critical literature review, a conceptual framework capturing all activities (inputs) of FSC was developed for Life Cycle Assessment of the UK FSC (see Figure 1). Secondary data were obtained from ONS and FAOSTAT covering the period from 1990 to 2014. Multiple linear regression (MLR) and Stochastic Frontier Analysis (SFA) was used to cross-check the reliability of data. MLR (Faul et al., 2009) is used to investigate the relationship the UK $\mathrm{CO}_{2} \mathrm{e}$ (as dependent variable) and FSC processes, both key factors and all activities that generate $\mathrm{CO}_{2} \mathrm{e}$ (as independent variables). SFA, as suggested by Aigner et al. (1977), is adopted and the works of Farrell (1959) and Meeusen and van Den Broeck (1977) are followed to estimate the technical efficiency of the decision-making units (i.e. selected countries and their fruits and vegetables supply to the UK). We choose the SFA over the alternative efficiency estimation approach, Data Envelopment Analysis (DEA) (Banker et al., 1984) because SFA has gained wide acknowledgment in the food, agriculture, economics and environmental literature (Lee and Tyler, 1978; Battese, and Coelli,1992; Coelli and Battese, 1996) due to its versatility, consistency with theory and relative ease of estimation (Baten et al., 2009). In that regard, the $\mathrm{CO}_{2} \mathrm{e}$ associated with the UK FSC is studied as a production function that relates the inputs (the key factors of $\mathrm{CO}_{2} \mathrm{e}$ captured by the conceptual framework) and output $\left(\mathrm{UK} \mathrm{CO}_{2} \mathrm{e}\right)$ with the aim of estimating the technical efficiency. We adopt MLR and SFA approaches to help explore the reliability of available data and test the conceptual framework of key factors of $\mathrm{CO}_{2} \mathrm{e}$ for circumstantial evidence. Multivariate data analysis approaches namely MLR and SFA - have the capability of making sense of limited data. Moreover, the use of MLR and SFA has offers the ability to statistically test the hypotheses, and also handle and examine multiple variables (determinants) (Cohen et al., 2013). Fahmy-Abdullah et al. (2018) and Song and Chen (2019) followed the SFA approach to study supply chain sector efficiency. Also, Ambrose et al. (2010) and Dubey et al. (2018) considered the MLR approach in the context of supply chains. However, both approaches are yet to be employed jointly in a single research work in the food supply chain context.

\subsection{Development of conceptual Framework of Key Factors of $\mathrm{CO}_{2} e$}

The conceptual framework of the study reveals collective ideas of the research studies from Pretty et al. (2005) and Smith et al. (2007). All $\mathrm{CO}_{2}$ e-related activities that take place throughout the FSC are considered and categorised into four main factors, and presented in Figure 1: (i) Growers' Field, (ii) Inland Logistics outside the UK, (iii) Transportation, and (iv) Sales and Distribution.

Growers' Field is used in this study to refer to all pre-farming activities, farming and F\&V harvesting activities. Growers' Field $\mathrm{CO}_{2} \mathrm{e}$ arise from the use of land, synthetic fertilisers, application of organic manure, use of organic soil, application of crop residues and burning of crop residues. Farming in the selected countries reflects these identified hotspots and activities (Tilman et al., 2011). The use of energy on fields is not included in our data due to the complexities of capturing them.

Inland logistics outside $\mathrm{UK} \mathrm{CO}_{2} \mathrm{e}$ include $\mathrm{CO}_{2} \mathrm{e}$ associated with on-farm transportation, storage (including heating, drying, ventilation, lighting) (Toka et al., 2015) and port logistics (transport to port areas for transportation) (Xue-gong, 2007). F\&V produced are transported from farming lands to warehouses where food is stored for further processing. Storage of $F \& V$ normally needs three days before they are transported to the UK. Activities at this point such as packaging and labelling generate considerable amounts of $\mathrm{CO}_{2} \mathrm{e}$ but most are excluded in this study due to lack of data. However, transport from the storage to the ports by heavy duty vehicles is included to Inland Logistics outside the UK.

Transportation is another factor of food supply chain. $\mathrm{CO}_{2} \mathrm{e}$ associated with the UK FSC are continuously discussed as a significant (Wakeland et al., 2012). F\&V imported to the UK are usually transported by Sea (transoceanic), road (heavy duty vehicles), air (airplanes) and rail (trains). These mode of transportation of $\mathrm{F} \& \mathrm{~V}$ from overseas are considered.

Sales and Distribution are considered as $\mathrm{CO}_{2} \mathrm{e}$ generated by delivery (transporting) $\mathrm{F} \& \mathrm{~V}$ from the ports to the wholesalers' warehouses in the UK, storage (awaiting distribution) and distribution (transporting) of F\&V to retailing shops. The complexity of capturing $\mathrm{CO}_{2} \mathrm{e}$ associated retailing shops and waste created by cosmetics standards of retailers and at home by consumers are not included in Sales and Distribution $\mathrm{CO}_{2} \mathrm{e}$ factor due to lack of data. Figure 1 provides the conceptual framework of the UK FSC considering all the stages of activities and hotspots that generate $\mathrm{CO}_{2} \mathrm{e}$ which culminates in the overall $\mathrm{UK} \mathrm{CO}_{2} \mathrm{e}$. 


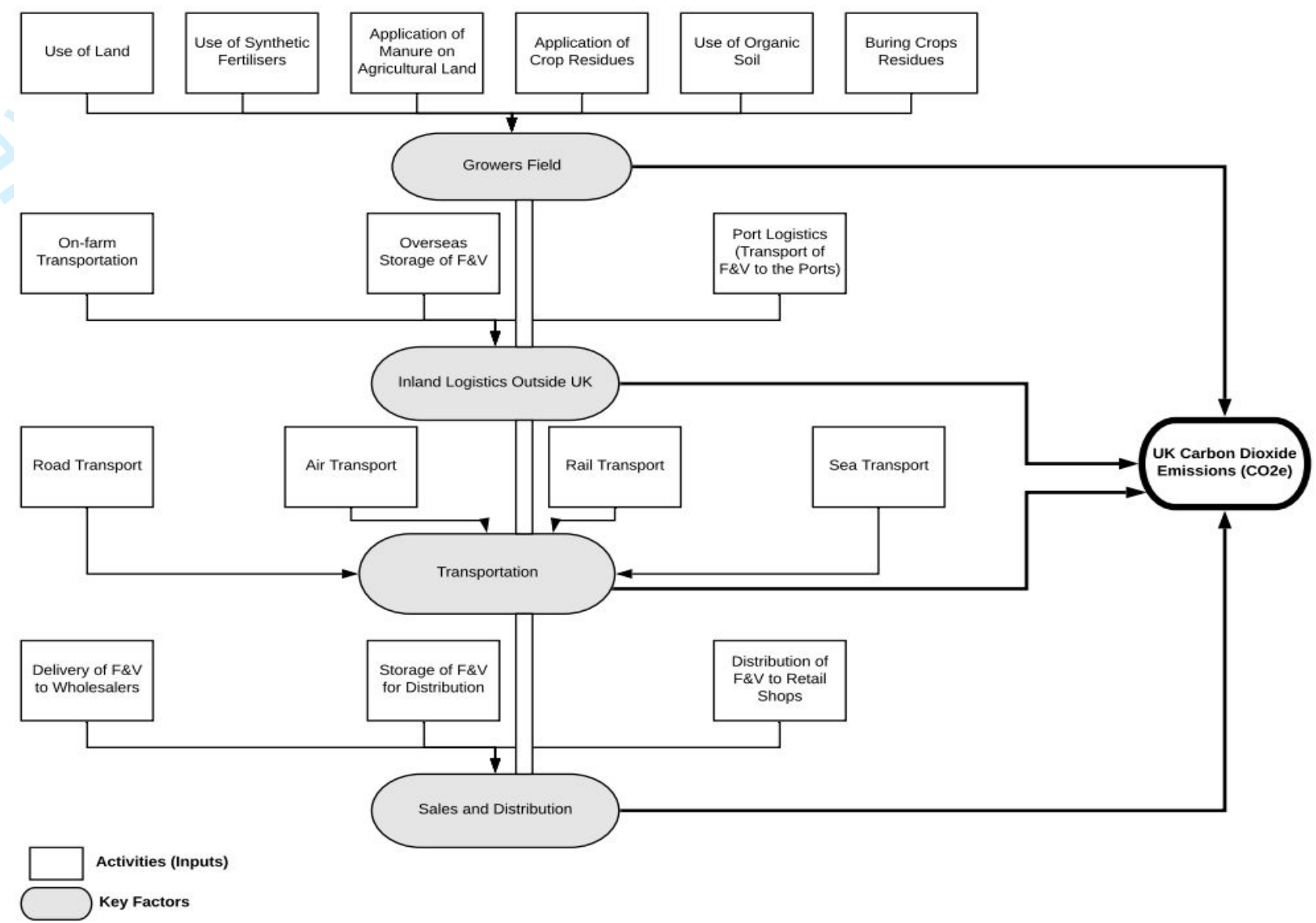

Figure 1. A conceptual framework of $\mathrm{CO}_{2} \mathrm{e}$ in the UK FSC

\subsection{Data Collection}

We use secondary data collected from FAOSTAT (2017) and ONS (2017). The sample observations, covering 1990 to 2014, are determined but there is lack of availability of most recent years for most of the selected countries. The result is a panel data with 400 observations, covering eight countries representing four continents (namely China and India for Asia; Colombia and Costa Rica for South America; France and Spain for Europe; and Ghana and South Africa for Africa). We selected these countries due to the increase in horticultural trade with the UK fostered by improved storage facilities, high quality, safety of produce and improved agricultural input - e.g., pesticides, seeds and fertilisers and irrigation methods (Dolan and Humphrey, 2004).

The key factors and all inputs captured by the conceptual framework are the explanatory variables and the dependent variable is the UK $\mathrm{CO}_{2} \mathrm{e}$. Table III presents the selected countries and their fresh fruit and vegetable supply to the UK, storage centres, storage before export and the exporting port centres. Table IV presents a summary of all input variables and explanations. Table $\mathrm{V}$ presents a summary of key factor variables, dependent variable and explanations used for the dataset. The utilisation of data is consistent with the work of Elhedhli and Merrick (2012) that provides $\mathrm{kg} \mathrm{CO}_{2}$ (direct) per tonne*km by a different mode of transportation, safe fruit and vegetable trade in the UK, and estimation of $\mathrm{CO}_{2} \mathrm{e}$ considering food miles.

Table III: Selected Countries, Fruit and Vegetables, Farming Community, Storage Facility Centre, Days of Storage and Ports for Export

\begin{tabular}{|c|c|c|c|c|c|}
\hline Country & $\begin{array}{c}\text { Selected } \\
\text { Fruit and } \\
\text { Vegetables }\end{array}$ & $\begin{array}{c}\text { Selected } \\
\text { Farmland/Farming } \\
\text { Community }\end{array}$ & $\begin{array}{c}\text { Storage Facility } \\
\text { Centres }\end{array}$ & $\begin{array}{l}\text { Days of } \\
\text { Storage }\end{array}$ & Export Centres/Ports \\
\hline China & $\begin{array}{l}\text { Banana } \\
\text { Pepper }\end{array}$ & Guangdong & $\begin{array}{l}\text { Guangdong Fruit, } \\
\text { Vegetable and Non- } \\
\text { staple Food } \\
\text { Company. }\end{array}$ & 3 & $\begin{array}{l}\text { Port of Shenzhen } \\
\text { Guangzhou Baiyun } \\
\text { International Airport, } \\
\text { Guangdong Sheng, } \\
\text { China }\end{array}$ \\
\hline Colombia & $\begin{array}{l}\text { Banana } \\
\text { Pineapple }\end{array}$ & $\begin{array}{l}\text { Colanta SA } \\
\text { company } \\
\text { Farmland, Girón, } \\
\text { Santander, }\end{array}$ & $\begin{array}{l}\text { Storage Facility, } \\
\text { Colanta, 66, Girón, } \\
\text { Santander, Colombia }\end{array}$ & 3 & $\begin{array}{l}\text { Barranquilla Port } \\
\text { El Dorado } \\
\text { International Airport }\end{array}$ \\
\hline
\end{tabular}


Colombia

\begin{tabular}{|c|c|c|c|c|c|}
\hline $\begin{array}{l}\text { Costa } \\
\text { Rica }\end{array}$ & $\begin{array}{l}\text { Melons } \\
\text { Banana }\end{array}$ & Limón Central & $\begin{array}{l}\text { Almacen Villalazo, } \\
\text { Limón, Siquirres, } \\
\text { Costa Rica }\end{array}$ & 3 & $\begin{array}{l}\text { Port of Puerto Limon } \\
\text { Limon International } \\
\text { Airport }\end{array}$ \\
\hline Spain & $\begin{array}{l}\text { Grapes } \\
\text { Lettuce }\end{array}$ & Province of Murcia & $\begin{array}{l}\text { Moving and Storage } \\
\text { La Seda, Mudanzas } \\
\text { y Guardamuebles La } \\
\text { Seda }\end{array}$ & 3 & $\begin{array}{l}\text { Noatum Container } \\
\text { Terminal Valencia, } \\
\text { Port of Madrid } \\
\text { Ciudad Real Airport }\end{array}$ \\
\hline France & $\begin{array}{l}\text { Apple } \\
\text { Tomatoes }\end{array}$ & D'aucy & $\begin{array}{l}\text { D'aucy, Prince de } \\
\text { Bretagne }\end{array}$ & 3 & $\begin{array}{l}\text { Nantes Saint-Nazaire } \\
\text { Port } \\
\text { Lann Bihoue Airport }\end{array}$ \\
\hline Ghana & $\begin{array}{l}\text { Banana } \\
\text { Pineapple }\end{array}$ & $\begin{array}{l}\text { Nyanyano, Kasoa, } \\
\text { Central, Ghana }\end{array}$ & $\begin{array}{l}\text { Jei River Farms } \\
\text { Awutu }\end{array}$ & 3 & $\begin{array}{l}\text { Tema Ports and } \\
\text { Harbours } \\
\text { Kotoka International } \\
\text { Airport, Accra }\end{array}$ \\
\hline India & $\begin{array}{l}\text { Mango } \\
\text { Banana }\end{array}$ & $\begin{array}{l}\text { Sericulture } \\
\text { Maharashtra }\end{array}$ & $\begin{array}{l}\text { Cold Chain Solution } \\
\text { of India }\end{array}$ & 3 & $\begin{array}{l}\text { JSW Jaigart Port } \\
\text { Chhatrapati Shivaji } \\
\text { International Airport }\end{array}$ \\
\hline $\begin{array}{l}\text { South } \\
\text { Africa }\end{array}$ & $\begin{array}{l}\text { Apple } \\
\text { Pears }\end{array}$ & $\begin{array}{l}\text { Elgin, Southern } \\
\text { Africa }\end{array}$ & Interpaarl Logistics & 3 & $\begin{array}{l}\text { Transnet Port } \\
\text { Terminals - Cape } \\
\text { Town } \\
\text { Cape Town } \\
\text { International Airport }\end{array}$ \\
\hline
\end{tabular}

Note: Three (3) days is the estimated days for storage based on the work of UNL (2017) that suggests safe standard for storing fruits and vegetables

Table IV. Selected Activities of the UK FSC (Input Variables)

\begin{tabular}{lll}
\hline Variable & Description of Variable & Authors' Calculation and Source of \\
(As presented in the model) & & Data Collection \\
& [multiple sources; but main source: \\
& FAOSTAT (2017)]
\end{tabular}

Land use This is the emissions produced by

(Land use)

Synthetic Fertilisers

(SF)

Manure Applied

(MA)

Crop Residues Applied

(CR)

Organic Soil

(OS)

Burning Residues

(BR)

On-farm transportation

(OFT) the use of cropland and land use

change by the country

This is the emissions produced by the use of synthetic fertilisers in a country for agricultural activities.

This is emissions produced by applying manures on agricultural soils by farmers.

This is emissions from crop residues and pasture renewal left on agricultural lands by farmers.

This is emissions from cultivated organic soils under cropland.

This is the emissions produced by the combustion of a portion of crop residues burnt on farming fields.

This is emissions from use of heavy-duty vehicles for transportation of fruits and
Calculation based on cropland emissions.

Calculation based on synthetic fertilisers emissions.

Calculation based on manure applied to soils emissions

Calculation based on crop residues on soils.

Calculation based on organic soil cropland emissions.

Calculation based on burning residue emissions.

Calculation based on heavy-duty transport emissions (as a proxy) for fuel and machinery use for 
vegetables from farmland to the overseas storage as a proxy for farm produce logistics.

Overseas storage (OVS)

\section{Port logistics}

(PL)

Road
(Hdv)

Air
(Plane)

Rail

(Train)

Sea

(Transoceanic)

Delivery

(DV)

Storage for Distribution (SfD)

Distribution

(Distr)
This is the emissions from storage of fruits and vegetables from overseas at the warehouses before transporting it to the port for export.

This is emissions from the transport of fruits and vegetables from the warehouse to the ports (either the airport or cargo port or train station).

This is emissions from road (heavyduty) transport of fruits and vegetables from home grown country to the UK.

This is emissions from air (plane) transport from fruits and vegetables from home grown country to the UK.

This is emissions from train transport of fruits and vegetables from home grown country to the UK

This is emissions from sea (transoceanic) transport of fruits and vegetables from home grown country to the UK.

This is emissions from transport of fruits and vegetables from the port by heavy-duty vehicles to warehouses of retailers in the UK.

This is emissions from storage of fruits and vegetables at the warehouse before transported to sales point warehouse.

Emissions from transport of fruits and vegetables from the storage (warehouse) in the UK to the transporting fruit and vegetables.

Calculation based on storage emissions provided by Wakeland $e t$ al. (2012) and work of UNL (2017).

Calculation based on distance from the overseas storage and emissions by heavy-duty vehicle transport of the fruits and vegetables.

Calculation based on distance from between the cities (home grown country capital and London, considering the location of the port) and emission by heavy-duty vehicle transport.

Calculation based on the air travel distance from between the cities (home grown country airport nearest to overseas storage and Heathrow airport) and emission by plane transport.

Calculation based on the travel distance from between the cities (home grown country rail station nearest to overseas storage and St. Pancras Station) and emission by train transport.

Calculation based on the travel distance from between the cities (home grown country cargo port station nearest to overseas storage and London Port) and emission by train transport.

Calculation based on the travel distance from the port in London to the retailer's large storage (warehouse) using Tesco Groceries Warehouse (as the storage point) and emission by heavy-duty vehicle transport.

Calculation based on storage emissions provided by Wakeland $e t$ al. (2012) and work of UNL (2017).

Calculation based on heavy-duty vehicle transport emissions of the fruit and vegetables from storage 
retailer's sale point by heavy-duty vehicles. (warehouse) in the UK to the retailer's sales point.

Notes: Detail of these calculations can be provided on request. All final values of variables are in tonnes of $\mathrm{CO}_{2} \mathrm{e}$.

Table V. Key Factor Variables and Dependent Variable

\begin{tabular}{ll}
\hline $\begin{array}{l}\text { Variable } \\
\text { (As presented in the model) }\end{array}$ & Description of Variable \\
\hline $\begin{array}{l}\mathrm{CO} 2 \mathrm{e} \\
\left(\mathrm{CO}_{2}\right)\end{array}$ & $\begin{array}{l}\text { UK Carbon dioxide emissions from all } \\
\text { sectors. }\end{array}$ \\
$\begin{array}{l}\text { Growers' Field } \\
(\mathrm{GF})\end{array}$ & $\begin{array}{l}\text { This is the emissions from the } \\
\text { summation of land use, synthetic } \\
\text { fertilisers, manure applied, crop } \\
\text { residues, organic soil and burning } \\
\text { residues emissions. }\end{array}$ \\
$\begin{array}{ll}\text { Inland Logistics outside the } \\
\text { UK }\end{array}$ & $\begin{array}{l}\text { This is emissions from the summation } \\
\text { on-farm transportation, storage of } \\
\text { fruits and vegetables (in overseas) and } \\
\text { port logistics. }\end{array}$
\end{tabular}

Calculation and Source of Data Collection

Office for National Statistics (2017)

Transportation

(Transportation)

This is transport emissions of fruits and vegetables from all the selected countries to the UK. It is the sum of variable road, air, rail and sea.

This is the emissions from delivery to retailer's warehouses, storage for distribution and distribution to retailer's shops. It is sum of the variables delivery, storage for distribution and distribution.
Based on the summation of emissions from land use, synthetic fertilisers, manure applied, crop residues, organic soil and burning residues from FAOSTAT (2017).

Based on the summation of emissions from on-farm transportation, overseas storage and port logistics from FAOSTAT (2017).

Based on the summation of emissions from all modes of transportation particularly by road (heavy-duty vehicles), air (planes), sea and rail. Calculation method adopted from Edwards-Jones et al. (2008) and Elhedhli and Merrick (2012

Author's calculation by addition of Delivery, Storage and Distribution emissions. Calculation method adopted from Edwards-Jones et al. (2008) and Elhedhli and Merrick (2012

Notes: Based on Author's calculation. All final values of variables are in tonnes of $\mathrm{CO}_{2} \mathrm{e}$.

\subsection{Model}

3.3.1 Multiple Linear Regression (MLR). To estimate the key factors, a multiple linear regression model is used for the panel data constructed using Eviews software (Thomsen et al., 2010). By estimating a function for the key factors of $\mathrm{CO}_{2} \mathrm{e}$ in the framework, the model is expressed as:

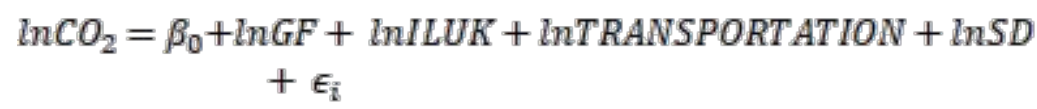
.....equation 1

where $\operatorname{lnCO}$, the dependent variable is the log of UK carbon dioxide emissions. $\beta_{0}$ is the constant. InGF is the $\log$ of Growers' Field; InILUK is the log of Inland Logistics outside the UK; lnTRANSPORTATION is the $\log$ of Transportation; and $\operatorname{lnSD}$ is the $\log$ of Sales and Distribution. $\epsilon_{i}$ is the error term. This study takes the natural logarithm of all the variables to correct all highly skewed variables into more approximately normal ones, to remove heteroskedasticity, and to handle an event of non-linearity relationship between dependent variable and explanatory variables (Lady, 2005). 
By estimating a function for all the activities (inputs) of key factors of $\mathrm{CO}_{2} \mathrm{e}$ in the framework, the model is expressed as

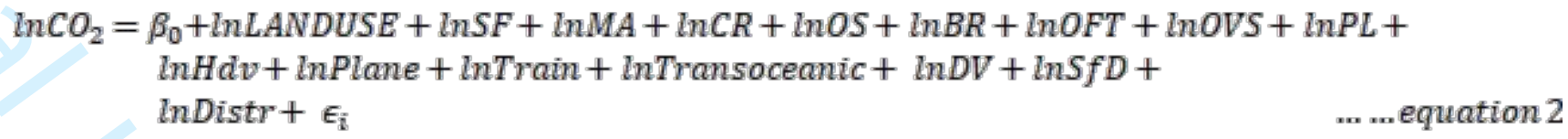

This model is adapted from the work of Aydin (2015) that uses MLR to determine key factors of energyrelated $\mathrm{CO}_{2} \mathrm{e}$ in Turkey. A computerised software, Eviews Version 6.0 (Thomsen et al., 2010) is used to analyse the key factors and all inputs of $\mathrm{CO}_{2} \mathrm{e}$ in the UK FSC.

3.3.2 Stochastic Frontier Analysis (SFA). SFA exists for estimating a model of technical efficiency scores. We assume technical efficiency (TE) which is an output-oriented measure (Coelli et al., 1998). This means the maximum output can be attained, given a set of inputs. The estimates, standard errors and mean efficiency are calculated using the stochastic production functional model (Meeusen and van Den Broeck, 1977). This

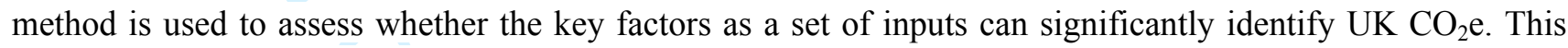
will help direct corrective measures and interventions towards the identified significant key factors of $\mathrm{CO}_{2} \mathrm{e}$ in the UK FSC. Under SFA, there are common functional forms in the literature - i.e. Quadratic, Translog function and Cobb-Douglas productions functions. This study uses the Cobb-Douglas Stochastic Frontier model due to the simple nature linearising with application of logarithms, providing a better functional form to estimate efficiency (Martins et al., 2012).

Therefore, the Cobb-Douglas stochastic frontier production model is estimated as:

$$
\begin{aligned}
\ln C 02_{i t}=\beta_{0} & +\beta_{1} \operatorname{lnGF}_{i t}+\beta_{2} \operatorname{lnILUK}_{i t}+\beta_{3} \text { InTransportation }_{i t}+\beta_{4} \operatorname{InSD}_{i t}+v_{i t} \\
& -U_{i t}
\end{aligned}
$$

$\ldots$.... equation 3

where the subscripts $i$ and $t$ represent the ith selected countries (sample) and the year of observation respectively, and $\mathrm{i}=1,2, \ldots \ldots . \mathrm{n} ; \mathrm{t}=1,2, \ldots \ldots \mathrm{n} ; \mathrm{CO}_{\text {it }}$ represents $\mathrm{UK} \mathrm{CO} 2 \mathrm{e} ; \mathrm{ILUK}_{\text {it }}$ represents Inland Logistics outside the UK; Transportation ${ }_{\text {it }}$ represents Transportation; and $\mathrm{SD}_{\text {it }}$ represents Sales and Distribution. "In" represents the natural logarithm. where the Technical efficiency is defined as:

$$
T E_{i t}=\frac{Y_{i t}}{Y_{i t}^{*}}=\frac{f\left(X_{i t} \beta\right) \exp \left(V_{i t}-U_{i t}\right)}{f\left(X_{i t} \beta\right) \exp \left(V_{i t}\right)}=\exp \left(-U_{i t}\right)
$$

where $\mathrm{U}_{\mathrm{it}}$ is the specifications of inefficiency. The model is estimated using a computer program, Frontier 4.1 suggested by Coelli (1996) to calculate the Maximum Likelihood Estimates (MLE) for the parameters of the Cobb-Douglas stochastic frontier production model.

\subsection{Empirical Results and Analysis}

\subsection{Identifying the key factors of $\mathrm{CO}_{2}$ e in UK food supply chains}

Hausman test investigates the preferred model between random effects and fixed effects estimator. When fixed effects estimator is preferred it means the null hypothesis is rejected. Fixed effects estimator has the benefit of capturing any effects that vary over time but are common across the whole panel data. Table VI presents the results of the fixed effects estimator as a preferred model by Hausman test (Hausman, 1978) after estimating equation 1 for the key factors of $\mathrm{CO}_{2} \mathrm{e}$. The $\mathrm{R}$-squared value of 0.585 explains that $58.5 \%$ of the variation in the $\log$ of $\mathrm{CO}_{2} \mathrm{e}$ can be explained by this model.

The results in Table VI show that Growers' Field and Inland Logistics outside the UK are not significant. This may be due to the complexity of the capture of overseas data and differences in measurement approach used by ONS and FAOSTAT. Nevertheless, the findings of other key factors such as Transportation and Sales and Distribution are significant. The results reveal that an additional increase in import by the modes of Transportation of fresh food predicts an increase in the $\mathrm{UK} \mathrm{CO}_{2}$ e by 10 tonnes of $\mathrm{CO}_{2} \mathrm{e}$ at $5 \%$ significance level. This is due to the burning of fossil fuel and long-distance travel of fresh food from global supply to the UK. This result is consistent with the work of Defra (2013) that a significant proportion of overall $\mathrm{UK} \mathrm{CO}_{2} \mathrm{e}$ is contributed by food transportation. Previous research by Marriott (2005) estimated $\mathrm{CO}_{2} \mathrm{e}$ associated with transportation of fresh fruits and vegetables from EU and non-EU countries, highlighting that a significant portion of $\mathrm{CO}_{2} \mathrm{e}$ are generated from the transport of fruits and vegetables. Also, Defra estimated tomatoes transport emissions to be $0.1 \mathrm{CO}_{2} \mathrm{e}$ per tonne of tomatoes from Spain to the UK (Garnett, 2006). While we were considering the global supply of fresh fruits and vegetables to the UK, we could evince increased 
importation and changes in modes of transportation over the period of the last decade. This study reveals transportation emissions of $10 \mathrm{CO}_{2}$ e per tonne of fresh fruits and vegetables to the UK.

In addition, this study finds an inverse relationship between Sales and Distribution emissions and UK $\mathrm{CO}_{2} \mathrm{e}$. Thus, the results reveal that a decrease of $\mathrm{UK} \mathrm{CO}_{2} \mathrm{e}$ of 1.3 tonnes of $\mathrm{CO}_{2} \mathrm{e}$ from Sales and Distribution per a tonne of fresh fruits and vegetables from global supply, ceteris paribus. It is statistically significant at the $1 \%$ level. This is due to the efficiency processes and measures used in the supply chain in the UK. The result is consistent with Hulthén and Gadde's (2009) emphasis that modified distribution facilities (e.g., trucks and distribution centres), when efficiently utilised, can reduce fuel consumption and $\mathrm{CO} 2 \mathrm{e}$.

Table VI. Key Factors of Carbon Dioxide Emissions

\begin{tabular}{lc}
\hline Variable & Coefficient \\
\hline Growers' field & $-0.000(0.001)$ \\
Inland Logistics outside the UK & $0.003(0.004)$ \\
Transportation & $0.100 * *(0.009)$ \\
Sales and Distribution & $-0.013^{* * *}(0.005)$
\end{tabular}

Summary Statistics:

Observation

R-squared

Adjusted R-squared

Prob(F-statistic)

Notes: ${ }^{* * *} \mathrm{p}<0.01,{ }^{* *} \mathrm{p}<0.05$ and ${ }^{*} \mathrm{p}<0.1$. The standard errors are the values in the parentheses. Prob (Fstatistic) showing the overall significant predicative capacity of the model.

\subsection{Identifying the significant inputs (activities) of Key Factors of $\mathrm{CO}_{2} \mathrm{e}$}

Using the model defined by equation 2, this study finds the existence of multicollinearity. Multicollinearity test is carried to remove coefficient estimates that have high dependence upon the correlation between the dependent and other predictor variables (He et al., 2018). Therefore, log of plane which has high coefficient is removed from equation 2 to estimate for inputs (activities) of key factors of $\mathrm{CO}_{2} \mathrm{e}$. From Table VII, fixed effects estimator is the preferred model by a Hausman test. The R-squared value of 0.631 explains that $63.1 \%$ of the variation in $\log$ of $\mathrm{CO}_{2} \mathrm{e}$ can be explained by this model. The results of all inputs (activities) of key factors of CO2e from MLR are presented in Table VII.

The results reveal that land use is statistically significant at $1 \%$, implying that an additional use of foreign land for fruits and vegetables produce to the UK will increase predicted $\mathrm{UK} \mathrm{CO}_{2} \mathrm{e}$ by 6.3 tonnes, ceteris paribus. This is consistent with the findings of Audsley et al. (2010) that explain that a proportion of $\mathrm{CO}_{2} \mathrm{e}$ from global land use changes are attributable to the UK food supply chain.

An inverse relationship is found for fruits and vegetables produced by organic soil and crop residues left on the soil. Both inputs of farm produce are statistically significant at $5 \%$. It indicates that an additional use of

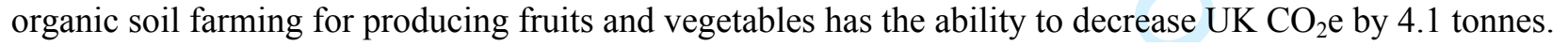
This is consistent with the work of Schahczenski and Hill (2009) which explains that organic agriculture has the ability to reduce $\mathrm{CO}_{2}$ e. Similar to organic soil farming, the results show that farming by crop residues on soils is expected to decrease $\mathrm{UK} \mathrm{CO}_{2} \mathrm{e}$ by 2.4 tonnes of carbon dioxide emissions, holding all other explanatory variables fixed. This result is consistent with the work of Mangalassery et al. (2014); who discuss that adopting zero tillage systems such as crop residue cover plays a significant role in reducing $\mathrm{CO}_{2} \mathrm{e}$. Other farm produce emissions inputs such as synthetic fertilisers, manure applied and burning crop residues are found not statistically significant.

On-farm transportation and port logistics (inputs of the key factor, Inland Logistics outside the UK) are not found significant. On the other hand, overseas storage indicates a positive relationship with $\mathrm{UK}_{\mathrm{CO}_{2} \mathrm{e}}$. Statistically, it shows that additional storage of fruits and vegetables at the overseas storage facilities increases the UK FSC $\mathrm{CO}_{2} \mathrm{e}$ by 6.2 tonnes, at a $1 \%$ significance level. This is consistent with the literature of Garnett (2006).

Results from different modes of transportation are very interesting. The findings reveal that road transport is significant, at the $10 \%$ level. The explanation for this can be that an additional transportation increase by road (heavy-duty vehicles) will increase $\mathrm{UK} \mathrm{CO}_{2} \mathrm{e}$ by 11 tonnes, ceteris paribus. $\mathrm{CO}_{2} \mathrm{e}$ associated with road transport is greater than other modes of transportation $\mathrm{CO}_{2} \mathrm{e}$ (Defra, 2013). This finding is consistent with 
findings from Greene and Plotkin (2011) that show that heavy-duty vehicles have the highest of the freight transportation and are increasing faster than other modes of transport, accounting for about $60 \%$.

Sea transport is significant at $10 \%$. The findings show that imports by additional sea transport (transoceanic) will increase UK $\mathrm{CO}_{2} \mathrm{e}$ by 2.9 tonnes of $\mathrm{CO}_{2} \mathrm{e}$. This indicates a positive relationship between UK $\mathrm{CO}_{2} \mathrm{e}$ and sea transport. The results are consistent with the study of Cadarso et al. (2010) that explained that significant proportion of overall $\mathrm{CO}_{2} \mathrm{e}$ is contributed by international freight transport emissions such as transoceanic traffic.

On rail transport, this paper finds rail transport significant at $1 \%$, and also predicts a possible reduction in $\mathrm{CO}_{2} \mathrm{e}$ by using improved rail transportation. The result indicates that additional journey by rail transport from the overseas countries to the UK offers the possibility of reducing $\mathrm{CO}_{2} \mathrm{e}$ by 7.8 tonnes of $\mathrm{CO}_{2} \mathrm{e}$. This is consistent with the literature of Jones (2002) that discusses that shift to more energy-efficient modes of transport such as rail transport that reduces transport-related energy consumption, leading to $\mathrm{CO}_{2} \mathrm{e}$ reduction.

Moreover, Delivery and Distribution inputs of Sales and Distribution are found non-significant. This may be due to the fact that major inputs such as packaging, retailer's storage and waste are not included in the key factors. Another reason can be attributed to the use of one retailer's storage and distribution centre (e.g., Tesco) for the calculation. In addition, the proximity or measurement used for the logistics and distribution $\mathrm{CO}_{2} \mathrm{e}$ in the UK may not be appropriate. Thus, other inputs mainly associated with logistics and distribution such as storage and use of fuel are excluded from the inputs. Nevertheless, the results show that storage for

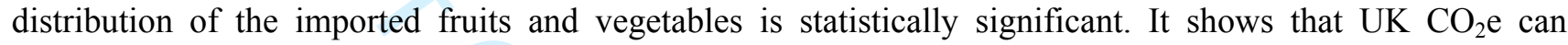
increase by 4.2 tonnes of $\mathrm{CO}_{2} \mathrm{e}$ from a storage facility provided for the fruits and vegetables. This is consistent with the work of Garnett (2011) that stresses that the fruit and vegetable sector does rely on cold storage. Adding that, cold storage provides a significant contribution to the UK's carbon dioxide emissions.

Therefore, the inputs of key factors that significantly contribute to $\mathrm{CO}_{2} \mathrm{e}$ in the UK FSC are road transport, land use, overseas storage, storage for distribution and sea transport. Furthermore, organic soil and crop residues farming are other inputs that significantly reduce $\mathrm{CO}_{2} \mathrm{e}$ in the UK FSC. Further, the key factors that significantly contribute to $\mathrm{CO}_{2} \mathrm{e}$ in the UK FSC are identified as Transportation and Distribution. Figure 2 presents ranking of significant key factors that contribute to $\mathrm{CO}_{2} \mathrm{e}$ in the UK FSC.

While some results of this study are consistent with the literature (e.g., Cadarso et al., 2010), we also have a few new findings that contribute to the existing literature. First, our results strongly recommend that 'improving Sales and Distribution activities can reduce CO2e in the UK FSC'. Second, our findings suggest that foreign land use, crop residue farming practices, organic farming practices, sea and rail transport contribute to $\mathrm{CO}_{2} \mathrm{e}$ in the UK FSC.

Table VII. Inputs (Activities) of Key Factors of $\mathrm{CO}_{2} \mathrm{e}$

Variable

Coefficient

Land use

$0.063 * * *(0.020)$

Synthetic Fertilisers

0.002(0.014)

Manure Applied

0.003(0.018)

Crop Residues Applied

$-0.024 * *(0.012)$

Organic Soil

$-0.041 * *(0.016)$

Burning Residues

$0.008(0.013)$

On-farm Transportation

20.553(12.666)

Overseas Storage

$0.062 * * *(0.016)$

Port Logistics

$-8.208(4.800)$

Road Transport

$0.110 *(0.065)$

Rail Transport

$-0.107 * * *(0.066)$

Sea Transport

$0.029 *(0.018)$

Delivery

$-12.444(7.880)$

Storage for Distribution

$0.042 * * *(0.014)$

Distribution

0.046(0.068) 
Summary Statistics

Observation

R-squared

Adjusted R-squared

Prob(F-statistic)

Notes: $* * * p<0.01, * * p<0.05$ and $* \mathrm{p}<0.1$. The standard errors are the values in the parentheses. Prob (Fstatistic) showing the overall significant predicative capacity of the model.

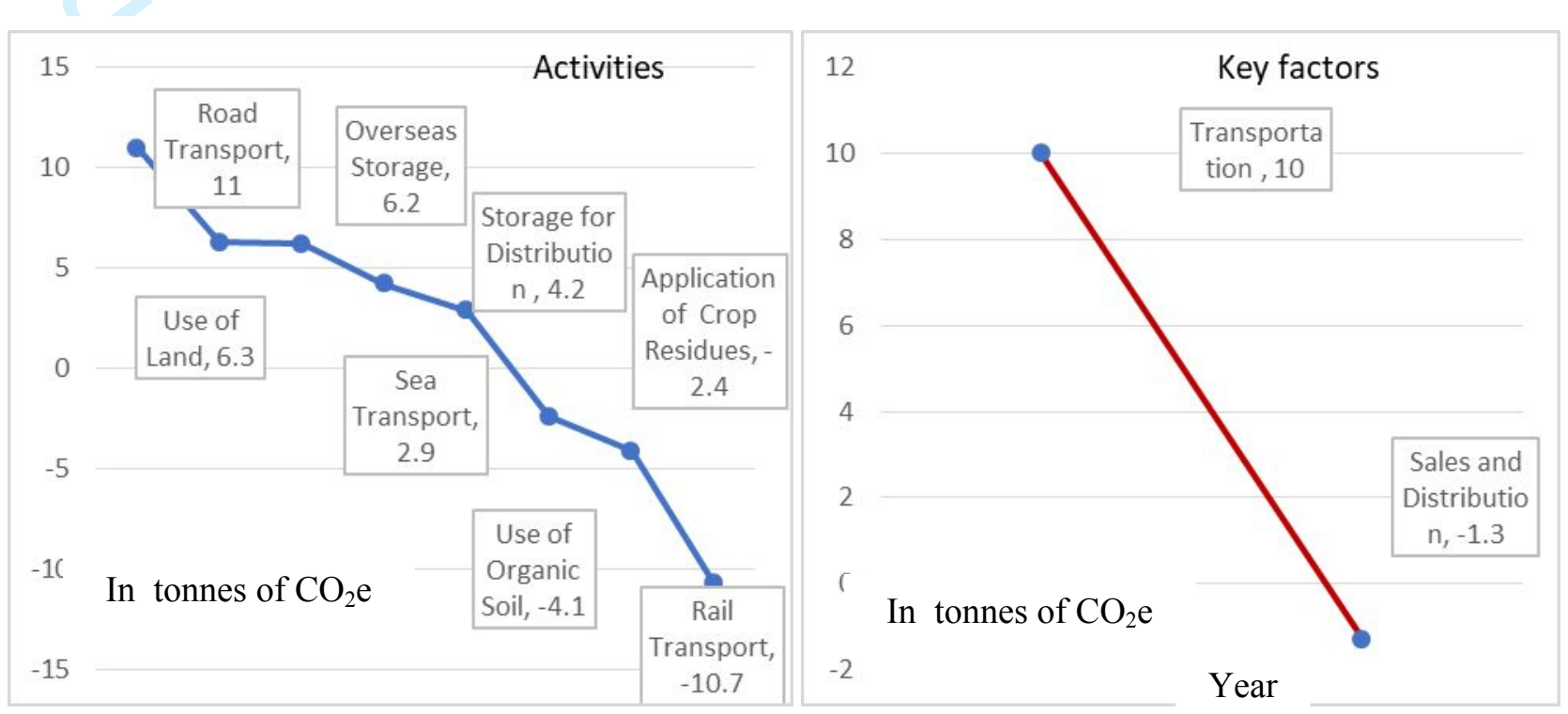

Figure 2. Ranking of significant inputs (activities) and key factors that contribute to $\mathrm{CO}_{2}$ emissions in UK food supply chains.

\subsection{Efficiency of the key factors in determining $\mathrm{CO}_{2}$ e in UK food supply chains}

Maximum Likelihood Estimates (MLE) of the coefficients of the stochastic frontier model is significantly better and preferred estimation model to Ordinary Least Squares (Coelli et al., 1998). Table VIII presents results of MLE of Cobb-Douglas Stochastic Frontier Model defined by equation 3. The results from MLE of Stochastic Frontier Analysis reveal all key factors (Growers' Field, Inland Logistics outside the UK, Transportation, and Sales and Distribution) are significant. This implies that the key factors are technically efficient to determine an increase or a decrease of the $\mathrm{CO}_{2} \mathrm{e}$ in the UK FSC (the output variable). Moreover, the mean efficiency of the key factors from the observation sample is estimated as $74.52 \%$. Therefore, the study reveals that the key factors used by the study can efficiently predict $\mathrm{CO}_{2} \mathrm{e}$ in the UK FSC by $74.52 \%$. This is consistent with the literature of Garnett (2011) and de Ruiter et al. (2016) that explain that significant amounts of $\mathrm{CO}_{2} \mathrm{e}$ are generated by the entire FSC. The existing inefficiency, which is $25.48 \%$, can be referred to as activities (input variables) such as use of energy, packaging, retailer's storage, household storage and waste which were not included in the key factors (in the data) due to their complexity. This can be explained in line with the work of Garnett (2006) which explains that some inputs (such as waste) are highly significant, and that $\mathrm{CO}_{2}$ e produced during harvesting, storage and transported should be accounted for. Also, Tassou et al's. (2014) research highlights significant $\mathrm{CO}_{2} \mathrm{e}$ generated throughout the $\mathrm{FSC}$, e.g., storage and waste. The sum of beta is less than 1 , showing a decreasing return to scale. This evidence is in line with falling trends of UK $\mathrm{CO}_{2} \mathrm{e}$ reported by OECD (2019) and ONS (2017). Despite an increase in the import of food, $\mathrm{UK} \mathrm{CO}_{2} \mathrm{e}$ generated by the FSC processes including Growers' Field and Transportation has not proportionally increased.

Further, the results reveal that Sales and Distribution which is positive and significant with high coefficient has the potential to have a greater effect on the output variable, $\mathrm{CO}_{2} \mathrm{e}$ (see Table VIII). This finding confirms the MLR results of this study in line with Hulthén and Gadde (2009). It further explains that improved logistics including modifying distribution facilities (e.g., trucks and distribution centres efficiently utilised) can reduce fuel consumption and $\mathrm{CO}_{2} \mathrm{e}$.

The minimum efficiency is $63.55 \%$ while the maximum is $79.39 \%$. In general, high technical efficiency was recorded for the total observations from 1990 to 2014. This shows that FSC professionals, researchers and other major stakeholders can rely on the findings of this study to initiate more practical measures directed towards the identified key factors of $\mathrm{CO}_{2} \mathrm{e}$ as a more reliable $\mathrm{CO}_{2} \mathrm{e}$ mitigation strategy to significantly contribute to the UK's vision of $\mathrm{CO}_{2}$ reduction emissions by $80 \%$ in 2050 . 
Both Transportation and Sales and Distribution are positive and have significant coefficients suggesting the importance of logistics in contributing to $\mathrm{CO}_{2} \mathrm{e}$ in the UK FSC. This confirms the estimate of MLR (see Table VI) which reveals similar results.

Table VIII. Maximum Likelihood Estimates of Cobb-Douglas Stochastic Frontier Production Model

Variable Parameter Coefficient

\begin{tabular}{lcc}
\hline Constant & $\beta_{0}$ & $-178.811^{* * *}(0.986)$ \\
Growers' Field & $\beta_{1}$ & $-0.106^{* *}(0.002)$ \\
Inland Logistics outside the UK & $\beta_{2}$ & $-152.467 * * *(0.734)$ \\
Transportation & $\beta_{3}$ & $37.569 * * *(0.146)$ \\
Sales and Distribution & $\beta_{3}$ & $114.974 * * *(0.684)$ \\
Sigma-Squared & $\Sigma$ & $4.339(3.659)$ \\
Gamma & $\Gamma$ & $1.000^{* * *}(0)$ \\
Log likelihood function & & -685.146 \\
LR test of the one-sided error & & 1618.042
\end{tabular}

Notes: ${ }^{* * *} \mathrm{p}<0.01,{ }^{* *} \mathrm{p}<0.05$ and ${ }^{*} \mathrm{p}<0.1$. The standard errors are the values in the parentheses.

\section{Discussions and Implications}

Following analysis and findings of this paper, it is clear that logistical services within the country for local distribution and third-party logistics (3PL) operators outside the sourcing country can improve logistics performance and also enhance the FSC effectiveness by reducing $\mathrm{CO} 2 \mathrm{e}$. This will involve exploring more feasible technological, operations-related, policy and legal-related measures.

\subsection{Technological and operation-related measures}

Improving efficiency is one of the technological and operation-related measures. This may include the use of solar, biogas, wind or hydrogen fuel cells as power plants. Most of the large ships are powered by power plants on the water which is associated with large amounts of $\mathrm{CO}_{2} \mathrm{e}$. So, a shift to more efficient energy sources such as biogas-fuelled ships can enhance in $\mathrm{CO}_{2} \mathrm{e}$ reduction in the FSC. Further, onboard energy management, smart voyage planning and hull and propeller optimisation in sea transport are additional efficient operational measures that can reduce $\mathrm{CO}_{2} \mathrm{e}$. In addition, businesses operations can shift to rail transport, particularly for inter-city transport and long distances transport, due to high $\mathrm{CO}_{2} \mathrm{e}$ associated with heavy-duty vehicles transport. Alternatively, transport mode shift from usual heavy-duty vehicles to hybrid electric vehicles can significantly reduce transport-generated $\mathrm{CO}_{2} \mathrm{e}$ (Fontaras et al., 2008). Furthermore, fuelefficient driving and driving operations can reduce fuel consumption and $\mathrm{CO}_{2} \mathrm{e}$ in the atmosphere (Ishii et al., 2008). With regards to that, heavy-duty vehicle drivers and staff can gain appropriate training and skills development in fuel-efficient driving and driving operations. Otherwise, using rail transport is more environmentally friendly and also helps enhance sustainable FSC. The rail transport is one of the common choices as it is energy-efficient, improves environmental performance, and reduces $\mathrm{CO}_{2} \mathrm{e}$ (Lammgard, 2012).

Also, improving storage energy systems can be one technological and operation-related measure that managers or businesses can explore. This includes the use of light-emitting diode lighting, innovative technologies and trailing edge in refrigeration, ventilation and heating equipment. Managers or businesses can increase the use of renewable energy such as biomass and biomass boilers. Using waste productsa for energy, plants and animal materials can also significantly reduce $\mathrm{CO}_{2} \mathrm{e}$ (Thornley et al., 2015). Tassou et al. (2014) argue that proper training for staff on behavioural changes in energy use is very important. Alternatively, the study of Sanchez-Rodrigues et al. (2014) can be utilised. Sanchez-Rodrigues et al.'s (2014) research stresses that shifting freight from road to rail in container movements between ports and inland destinations in the UK will reduce $\mathrm{CO}_{2} \mathrm{e}$. Additionally, rerouting containers away from usual large ports in the UK Southeast and making use of the North-west and Northern ports for the distribution of imports can reduce $\mathrm{CO}_{2} \mathrm{e}$. Nonetheless, the use of rerouting technique, practices and principles of decarbonisation of logistics can be used (McKinnon and Piecyk, 2012). For example, managers can set $\mathrm{CO}_{2}$ emission reduction targets in logistics operations by 
redefining logistics emissions targets and applying this initiative to the entire logistics operations in respect of the carbon trade-offs that exist between all logistical operations and services.

\subsection{Policy and legal-related measures}

Maintaining environmentally sustainable business objectives is a big challenge for global operators. Many companies around the globe are progressing towards incorporating green practices including green supply chain management and green logistics (Ahi and Searcy, 2013). These initiatives can enable businesses to achieve environmental sustainability goals that consider $\mathrm{CO}_{2} \mathrm{e}$ reduction targets. In addition to that FSC businesses can ensure that suppliers or stakeholders share similar greener objectives or goals. This will enable control or reduction of $\mathrm{CO}_{2} \mathrm{e}$ in various processes/services by the logistical services and 3PL operators.

Moreover, other major stakeholders such as the governments, advocates, institutions, the third sector and researchers can create and promote certain initiatives to contribute to $\mathrm{CO}_{2} \mathrm{e}$ reduction in the FSC. First, in the Kyoto Protocol, plane and transoceanic transport are not included (Saunders and Hayes, 2007). Advocates and governments can suggest the inclusion of these significant emissions factors (hotspots) to the Kyoto Protocol. This will enable governments to apply more stringent policy mechanisms to achieving $\mathrm{CO}_{2}$ emission targets in sea and airplane transportation. Additionally, governments can adopt or encourage policies such as mobility management programmes, urban redevelopment, privatisation and public-private partnerships to enhance better transportation systems and infrastructure to continuously reduce $\mathrm{CO}_{2} \mathrm{e}$ from food trade.

Second, logistics and supply chains managers from emerging economies can integrate low-carbon policies and practices into their operations which could become the organisation's competitive advantage while contributing to a more sustainable society. Integrating low-carbon policies and measures involves planning, implementation and maintaining carbon efficiency of business activities and processes. The practices should entail low-carbon products, low-carbon production and low-carbon logistics (de Sousa Jabbour et al., 2019).

Moreover, retailers can stress the importance of buying organic foods to advance sustainable FSCs. Notwithstanding that, Barrett et al. (2013) argue that a strong consumption-based policy research approach would enable the UK to improve sustainable consumption and production policies. This would create sustainability roadmap that can be easily followed by all stakeholders (including farmers, logistics businesses, retailers and customers) to reducing $\mathrm{CO}_{2} \mathrm{e}$. This can be facilitated by first measuring the supply-side and demand-side indicators of consumption of fruits and vegetables empirically, considering all players to have better assessment and allocate appropriate policies to help achieve targets. To achieve this, institutions, researchers and experts can collaborate to enhance consistency, robustness and reliability of approaches and methods for CO2e reduction. Furthermore, Sundarakani et al.'s (2010) suggestions can be adopted by businesses and FSC players to enhance mitigation of the $\mathrm{CO}_{2} \mathrm{e}$ across the food supply chain, through the following: (I) adding rates of carbon emission to criteria for supplier selection; (II) design FSC with CO2e in mind concurrently; (III) design green buying and supplying policies; (IV) use innovations in logistics services to reduce $\mathrm{CO} 2 \mathrm{e} ;(\mathrm{V})$ design distribution strategies that promote recycling at the end of consumption; (VI) create substantial awareness among consumers on $\mathrm{CO}_{2} \mathrm{e}$.

Importantly, Lang and Schoen (2016) question why the UK import apples or pears which could be grown locally. Efforts should be channelled towards intensifying locally produced fresh food, while solely importing the fresh food that cannot be grown in the UK e.g., mangoes and pineapples. Although UK locally produced fruits (e.g., apples and pears) are more sustainable and generate significantly less waste than importation of tropical fruits (Hendry et al., 2019), the entire supply chain culminates in $\mathrm{CO}_{2}$ emissions. Global warming could also be affecting the UK local production of fruits, so innovative measures and practices can be implemented to expand the growing season of locally grown fruits which will have better environmental benefits. This discussion provides insights into technological and operations-related and policy and legalrelated measures as a fast-track approach to reducing $\mathrm{CO}_{2} \mathrm{e}$ in the UK FSC. In addition, other measures and initiatives that can be explored to mitigate $\mathrm{CO}_{2} \mathrm{e}$ are suggested - e.g., use of biomass energy and carbon sequestration. In additon, the findings and analysis can help other countries to rethink the impact of $\mathrm{CO}_{2} \mathrm{e}$ on their food trade and promote local production. In addition, while key activities, e.g., food waste, were not captured in the study, future researchers can consider food waste assessment of a specific food category from different regions and also could compare this with locally produced ones.

\section{Conclusions}

This paper uses multivariate approaches (multiple linear regression and stochastic frontier analysis) to analyse ONS and FAO data covering the period from 1990 to 2014 to identify key factors of $\mathrm{CO}_{2} \mathrm{e}$ in the UK food supply chains. The re-defined LCA tool applied is an all-inclusive assessment, which covers the entire food supply chain starting from overseas sources.

This study finds that Transportation and Sales and Distribution are the two key factors of $\mathrm{CO}_{2} \mathrm{e}$ in the UK FSC by the regression approach. Additionally, SFA results confirm that the key factors are sufficient to predict an increase or decrease in $\mathrm{CO}_{2} \mathrm{e}$ in the UK FSC. This paper contributes to the existing literature and fills an 


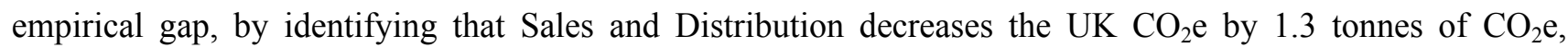
through improved technological approaches used in logistical services, sales, and distribution in the UK. This paper also supports previous studies by McKinnon and Piecyk (2012) and Defra (2013) that estimated that transportation contributes a significant amount of $\mathrm{CO}_{2} \mathrm{e}$ in the UK FSC. Further, the SFA reveals the key factors that can efficiently predict $\mathrm{CO}_{2} \mathrm{e}$ in the UK FSC by $74.52 \%$. The inefficiency that exists can be explained by the inputs of the key factors that are not included in data collection - e.g., use of energy, packaging and waste.

Analysis from the two multivariate methods (MLR and SFA) clarifies that interventional, realistic and practical measures can be directly explored identifying key factors as a more reliable mitigation approach to reducing $\mathrm{CO}_{2} \mathrm{e}$ in the UK FSC.

While supply chain actors, e.g., retailers, can continue to increased use of carbon labelling and carbon foot printing as backdoor measures to educate consumers on low-carbon products, we suggest more technological and operations-related measures and feasible policy and legal-related measures. These can serve as vital mitigating measures for a significant amount of $\mathrm{CO}_{2} \mathrm{e}$ generated by the UK FSC. These measures include maintaining greener objectives across the FSC network, improving efficiency in the use of logistics and storage facilities, integration of low-carbon policies and practices into operation, and adopting governmental policies such as privatisation and urban redevelopment to enhance better transportation systems and infrastructure.

\subsection{Key contributions}

Our study makes three critical contributions to the literature and practice. First, we re-define LCA as an allinclusive assessment tool which entails measuring environmental and other related impacts (mainly $\left.\mathrm{CO}_{2} \mathrm{e}\right)$ starting from overseas sources. To achieve a complete picture of LCA, all activities generating $\mathrm{CO}_{2} \mathrm{e}$ in the supply chains in their entirety need to be measured and included in the LCA. This assessment approach has been missing in the extant literature of social sciences. To the best of our knowledge, if any attempt is made by previous studies, the LCA would only consider a few aspects or activities within the supply chain, e.g., transportation and waste. We suggest re-defined LCA tool to be considered as a holistic approach tool starting from overseas sources.

Second, our methodological approach that considered the use of multivariate methods (regression and stochastic frontier analysis) to analyse the secondary data is somewhat novel and it makes a solid contribution. This approach suggests an advanced, more robust measurement of determining $\mathrm{CO}_{2} \mathrm{e}$ within the supply chains. Knowing that we have solid background on and justification for the $\mathrm{CO}_{2} \mathrm{e}$ estimated, we can initiate appropriate sustainable policies and measures to enhance sustainable food supply chains. This approach has not been explored widely in the past and this can also be extended to other areas of study.

Third, our findings are unique and make empirical contributions to the current literature. While studies are yet to estimate efficiency of the activities in determining $\mathrm{CO}_{2} \mathrm{e}$, our paper represents a solid piece work to suggest the step forward. It also helps readers in operations and supply chain management to understand key factors that can be properly channelled to enhance sustainability and support extra global competitive edge. We have also properly aligned the findings with policies and measures for both businesses and governments. We believe these are unique and deserve attention.

\subsection{Limitations and research opportunities}

This study has some limitations. The first limitation is related to the theoretical perspective. It is important to align the research with organisational theories to help develop theoretical contributions and insights into different organisational theories, e.g., ecological modernisation theory and resource-based view. As our paper is focusing on the $\mathrm{CO}_{2} \mathrm{e}$ aspect of sustainability, the scientific and ecological management sides of the FSC are not considered. Some of the established theories of operations management such as the resource-based view and stakeholder theory may help to relate available organisational resources efficiently to reduce $\mathrm{CO}_{2} \mathrm{e}$ and may also help to involve the import/export businesses to control carbon emissions through strict measures. Future research can consider this theoretical aspect of the study. Second, data that we collected did not cover current years; they only covered 1990 to 2014. This is due to large amounts of missing data in the dataset pertaining to $2015-2017$ at the time of our data collection. This is mainly because of limited availability of data for the sample countries and the selected fruits and vegetables of the sample countries. Likewise, important activities such as food waste and packaging were excluded in the re-defined LCA of the UK food supply chains due to complexity of data and estimation, and the lack of availability of data. Further studies can collect data from different online sources, e.g., UN Comtrade (International Trade Statistics Database) to complement ONS and FAOSTAT data. Moreover, researchers can consider food waste assessment of specific food categories from different regions and also compare these with locally produced ones. In addition, this study finds Growers' field data non-significant due to different activities (variables) comprising these data. Therefore, future researchers can adopt different mathematical calculations (e.g., Differential equations and Cauchy-Riemann equations) for estimation of Growers' Field data. 
Further studies can consider research opportunities in Sustainability Impact Assessment (SIA) of the UK FSC. This can provide more insights into the impact of activities of the supply chains that contribute to $\mathrm{CO}_{2} \mathrm{e}$ in the UK FSC. Other researchers can also consider technological inclusion in FSC.

Acknowledgement: We presented this research in EurOMA 2018. We would like to thank the reviewers of the EurOMA Committee for selecting this paper for the special issue of the IJOPM from the EurOMA Conference.

\section{References}

AHDB. (2016), "What might Brexit mean for UK trade in horticultural products?", available at: https://ahdb.org.uk/brexit/documents/Horticulture_bitesize.pdf (accessed December 7, 2017).

Ahi, P. and Searcy, C. (2013), "A comparative literature analysis of definitions for green and sustainable supply chain management”, Journal of Cleaner Production, Vol. 52, pp.329-341.

Aigner, D., Lovell, C.K. and Schmidt, P. (1977), "Formulation and estimation of stochastic frontier production function models", Journal of Econometrics, Vol. 6 No. 1, pp.21-37.

Ambrose, E., Marshall, D. and Lynch, D. (2010), "Buyer supplier perspectives on supply chain relationships". International Journal of Operations \& Production Management, Vol. 30 No. 12, pp.1269-1290.

Audsley, E., Brander, M., Chatterton, J.C., Murphy-Bokern, D., Webster, C. and Williams, A.G. (2010), "How low can we go? An assessment of greenhouse gas emissions from the UK food system and the scope reduction by 2050", Report for the WWF and Food Climate Research Network.

Aydin, G. (2015), "The development and validation of regression models to predict energy-related CO2e in Turkey", Energy Sources, Part B: Economics, Planning, and Policy, Vol. 10 No. 2, pp.176-182.

Baiocchi, G., and Minx, J. (2010), "Understanding changes in the UK's CO2e: A global perspective", Environmental Science and Technology, Vol. 44 No. 4, 1177-1184.

Banker, R.D., Charnes, A. and Cooper, W.W. (1984), "Some models for estimating technical and scale inefficiencies in data envelopment analysis", Management science, Vol. 30 No. 9, pp.1078-1092.

Barrett, J., Peters, G., Wiedmann, T., Scott, K., Lenzen, M., Roelich, K. and Le Quéré, C. (2013), "Consumption-based GHG emission accounting: a UK case study", Climate Policy, Vol. 13 No. 4, pp.451-470.

Baten, M.A., Kamil, A.A. and Fatama, K. (2009), "Technical efficiency in stochastic frontier production model: an application to the manufacturing industry in Bangladesh", Australian Journal of Basic and Applied Sciences, Vol. 3 No. 2, pp.1160-1169.

Bates, R.L., Chambers, N.G. and Craig, L.C.A. (2019), "Greenhouse gas emissions of UK diets". Proceedings of the Nutrition Society, Vol. 78. (OCE2).

Battese, G.E. and Coelli, T.J. (1992), "Frontier production functions, technical efficiency and panel data: with application to paddy farmers in India). Journal of Productivity Analysis, Vol. 3 No.1, pp.153-169.

Brand, C. and Preston, J.M. (2010), “"60-20 emission' - the unequal distribution of greenhouse gas emissions from personal, non-business travel in the UK", Transport Policy, Vol 17 No. 1, pp.9-19.

Cadarso, M.Á., López, L.A., Gómez, N. and Tobarra, M.Á. (2010), "CO2e of international freight transport and offshoring: measurement and allocation", Ecological Economics, Vol. 69 No. 8, pp.1682-1694.

Caro, D. (2019), "Carbon Footprint”. Encyclopedia of Ecology (Second Edition), Vol. 4, pp252 -257.

Coelli, T.J. (1996), "A guide to FRONTIER 4.1: A computer program for stochastic frontier production and cost estimation", Centre for Efficiency and Productivity Analysis Working Paper, Vol. 96 No. 07.

Coelli, T.J. and Battese, G.E. (1996), "Identification of factors which influence the technical inefficiency of Indian farmers. Australian Journal of Agricultural Economics", Vol. 40 No. 2, pp.103-128.

Coelli, T.J., Rao, D.P., O’Donnell, C.J. and Battese, G.E. (1998), “An introduction to productivity and efficiency analysis". Springer Science: New York.

Cohen, J., Cohen, P., West, S.G. and Aiken, L.S. (2013), “Applied multiple regression/correlation analysis for the behavioral sciences". Routledge.

Coley, D., Howard, M. and Winter, M. (2011), "Local food, food miles and carbon emissions: A comparison of farm shop and mass distribution approaches", Food policy, Vol. 34 No. 2, pp.150-155.

Committee on Climate Change. (2019), "Reducing UK emissions 2019 Report to Parliament, available at: https://www.theccc.org.uk/wp-content/uploads/2019/07/CCC-2019-Progress-in-reducing-UKemissions.pdf (accessed March 27, 2020).

Curran, M.A. (1996), "Environmental life-cycle assessment", The International Journal of Life Cycle Assessment, Vol. 1 No. 3, pp.179-179. 
Curran, M.A. (2008), "Human Ecology: Life Cycle Assessment", Encyclopedia of Ecology, Five-Volume Set, ISBN-13: 978-0-444-52033-3

Davis, S.J. and Caldeira, K. (2010), "Consumption-based accounting of CO2e", Proceedings of the National Academy of Sciences, Vol. 107 No.12, pp.5687-5692.

de Ruiter, H., Macdiarmid, J.I., Matthews, R.B., Kastner, T. and Smith, P. (2016), "Global cropland and greenhouse gas impacts of UK food supply are increasingly located overseas", Journal of the Royal Society Interface, Vol. 13 No. 114, p.20151001.

de Sousa Jabbour, A.B.L., Chiappetta Jabbour, C.J., Sarkis, J., Gunasekaran, A., Furlan Matos Alves, M.W. and Ribeiro, D.A. (2019), "Decarbonisation of operations management-looking back, moving forward: a review and implications for the production research community". International Journal of Production Research, Vol. 57 No. 15, pp.4743-4765.

Defra. (2012), "Food Statistics Pocketbook 2012", available at: https://www.gov.uk/government/uploads/system/uploads/attachment_data/file/183302/foodpocketbook2012edition-09apr2013.pdf (accessed October 19, 2017).

Defra. (2013), "Food Statistics Pocketbook 2013", available at: https://www.gov.uk/government/uploads/system/uploads/attachment_data/file/315418/foodpocketbook2013update-29may14.pdf (accessed August 7, 2017).

Defra. (2017a), "UK's Carbon Footprint 1997 - 2016", available at: https://assets.publishing.service.gov.uk/government/uploads/system/uploads/attachment_data/file/79455 7/Consumption_emissions_April19.pdf (accessed May 21, 2019).

Defra. (2017b), "Bringing fruit, vegetables and plant products into the UK", available at: https://www.gov.uk/government/uploads/system/uploads/attachment_data/file/531618/Bringing_fruit veg_and_plants_into_the_UK_leaflet.pdf (accessed August 11, 2017).

Dolan, C., and J. Humphrey. (2004), "Changing Governance Patterns in the Trade in Fresh Vegetables between Africa and the United Kingdom", Environment and planning A, Vol. 36 No. 3, pp.491-509.

Du, Y., Yi, Q., Li, C. and Liao, L. (2015), "Life cycle oriented low-carbon operation models of machinery manufacturing industry". Journal of Cleaner Production, Vol. 91, pp.145-157.

Dubey, R., Altay, N., Gunasekaran, A., Blome, C., Papadopoulos, T. and Childe, S.J. (2018), "Supply chain agility, adaptability and alignment". International Journal of Operations \& Production Management, Vol. 38 No.1, pp 129-148.

Edwards-Jones, G., i Canals, L.M., Hounsome, N., Truninger, M., Koerber, G., Hounsome, B., Cross, P., York, E.H., Hospido, A., Plassmann, K. and Harris, I.M. (2008), "Testing the assertion that 'local food is best': the challenges of an evidence-based approach", Trends in Food Science \& Technology, Vol. 19 No. 5, pp.265-274.

Elhedhli, S. and Merrick, R. (2012), "Green supply chain network design to reduce carbon emissions", Transportation Research Part D: Transport and Environment, Vol. 17 No. 5, pp.370-379.

Fahmy-Abdullah, M., Sieng, L.W. and Isa, H.M. (2018), "Technical Efficiency in Malaysian Textile Manufacturing Industry: A Stochastic Frontier Analysis (SFA) Approach". International Journal of Economics \& Management, Vol. 12 No. 2

FAOSTAT. (2017), “Agricultural Total”, available at FAOSTAT database: http://www.fao.org/faostat/en/\#data/GT (accessed August 6, 2017).

Farrel, M.J. (1959), "The measurement of productive efficiency”, Journal of the Royal Statistical Society, Series A General, Vol. 125, pp.252-267.

Faul, F., Erdfelder, E., Buchner, A. and Lang, A.G. (2009), "Statistical power analyses using G* Power 3.1: Tests for correlation and regression analyses", Behaviour Research Methods, Vol. 41 No. 4, pp.11491160.

FCRN. (2015), "Chapter 3: Food systems and greenhouse gas emissions", available at: https://foodsource.org.uk/sites/default/files/chapters/pdfs/foodsource chapter 3.pdf (accessed March $25,2020)$

Finnveden, G., Hauschild, M.Z., Ekvall, T., Guinée, J., Heijungs, R., Hellweg, S., Koehler, A., Pennington, D. and Suh, S. (2009), "Recent developments in life cycle assessment", Journal of Environmental Management, Vol. 91 No.1, pp.1-21.

Fontaras, G., Pistikopoulos, P. and Samaras, Z. (2008), "Experimental evaluation of hybrid vehicle fuel economy and pollutant emissions over real-world simulation driving cycles", Atmospheric environment, Vol. 42 No. 18, pp.4023-4035.

Gadema, Z. and Oglethorpe, D. (2011), "The use and usefulness of carbon labelling food: a policy perspective from a survey of UK supermarket shoppers", Food policy, Vol. 36 No. 6, pp.815-822.

Garnett, T. (2006), Fruit and vegetables \& UK greenhouse gas emissions: exploring the relationship. UK: Food and Climate Research Network, University of Surrey. 
Garnett, T. (2011), "Where are the best opportunities for reducing greenhouse gas emissions in the food system (including the food chain)?", Food policy, Vol. 36, pp. S23-S32.

Greene, D.L. and Plotkin, S.E. (2011), Reducing Greenhouse Gas Emissions from US Transportation. Pew Center on Global Climate Change, Arlington.

Hausman, J.A. (1978), "Specification tests in econometrics", Econometrica: Journal of the Econometric Society, pp.1251-1271.

He, B., Pan, Q. and Deng, Z. (2018), "Product carbon footprint for product life cycle under uncertainty", Journal of Cleaner Production, Vol. 187, pp.459-472.

Hendry, L.C., Stevenson, M., MacBryde, J., Ball, P., Sayed, M. and Liu, L. (2019), "Local FSC resilience to constitutional change: the Brexit effect", International Journal of Operations \& Production Management, Vol. 39 No. 3, pp.429-453.

Hulthén, K. and Gadde, L.E. (2009), "Sustainable distribution networks-challenges and opportunities. Industrial Marketing and Purchasing Group", available at: www. impgroup. org/uploads/papers/7105.pdf (accessed at 01.03. 2013).

International Trade Centre. (2012), "Product Carbon Footprinting Standards in the Agri-food Sector". Geneva, Switzerland: ITC, available at: http://www.intracen.org/Product-Carbon-FootprintingStandards-in-the-Agri-Food-Sector/ (accessed May 8, 2018).

Ishii, J., Osuga, M., Okada, T., Miyazaki, H., Koseki, M. and Tanikoshi, K. (2008), "Reduction of CO2e for automotive systems", Hitachi Review, Vol. 57 No. 5, p.185.

Jensen, J.K., 2012. "Product carbon footprint developments and gaps", International Journal of Physical Distribution and Logistics Management, Vol. 42 No. 4, pp.338-354.

Jones, A. (2002), "An environmental assessment of food supply chains: a case study on dessert apples", Environmental management, Vol. 30 No. 4, pp.560-576.

Krishna, I.M., Manickam, V., Shah, A. and Davergave, N. (2017), Environmental management: science and engineering for industry. Butterworth-Heinemann.

Lady. E. L. (2005), "The Logarithm Function", available at: http://www.math.hawaii.edu/ lee/calculus/Logarithm.pdf (accessed August 17, 2017).

Lammgard, C. (2012), "Intermodal train services: a business challenge and a measure for decarbonisation for logistics service providers", Research in Transportation Business \& Management, Vol. 5, pp. 48-56.

Lang, T. and Schoen, V. (2016), "Food, the UK and the EU: Brexit or Bremain?", UK: Food Research Collaboration.

Lee, L.F. and Tyler, W.G. (1978), "The stochastic frontier production function and average efficiency: An empirical analysis", Journal of Econometrics, Vol. 7 No. 3, pp.385-389.

Lenzen, M. (2000), "Errors in Conventional and Input-Output-based Life-Cycle Inventories", Journal of Industrial Ecology, Vol. 4 No. 4, pp.127-148.

López, L.A., Cadarso, M.A., Gómez, N. and Tobarra, M.Á. (2015), "Food miles, carbon footprint and global value chains for Spanish agriculture: assessing the impact of a carbon border tax", Journal of Cleaner Production, Vol. 103, pp.423-436.

Mangalassery, S., Sjögersten, S., Sparkes, D.L., Sturrock, C.J., Craigon, J. and Mooney, S.J. (2014), "To what extent can zero tillage lead to a reduction in greenhouse gas emissions from temperate soils?", Scientific reports, Vol. 4, p.4586.

Marriott, C. (2005), "From Plough to Plate by Plane: An investigation into trends and drivers in the airfreight importation of fresh fruit and vegetables into the United Kingdom from 1996 to 2004", Guildford: University of Surrey.

Martins, F.G.D., Silva, F.G.F.D., Rocha, C.H., Queiroz, M. and Araújo, C.E.F. (2012), “Analysis of efficiency of the regulated transportation coach operator by stochastic frontier of Cobb-Douglas and translog functions: the case of the interstate passenger coach transportation in Brazil", Journal of Transport Literature, Vol. 6 No. 3, pp.08-33.

McCarthy, D., Matopoulos, A. and Davies, P. (2015), "Life cycle assessment in the food supply chain: a case study", International Journal of Logistics Research and Applications, Vol. 18 No. 2, pp.140-154.

McKinnon, A.C. and Piecyk, M.I. (2012), "Setting targets for reducing carbon emissions from logistics: current practice and guiding principles", Carbon Management, Vol. 3 No. 6, pp.629-639.

Meeusen, W. and van Den Broeck, J. (1977), "Efficiency estimation from Cobb-Douglas production functions with composed error", International Economic Review, pp.435-444.

Michalský, M. and Hooda, P.S. (2015), "Greenhouse gas emissions of imported and locally produced fruit and vegetable commodities: A quantitative assessment”, Environmental Science \& Policy, Vol. 48, pp.3243.

Mogensen, L., Hermansen, J.E., Halberg, N., Dalgaard, R., Vis, J.C. and Smith, B.G. (2009), "Life cycle assessment across the food supply chain", Sustainability in the food industry, pp.115-144. 
Moxham, C. (2004) "FSC Management", International Journal of Operations \& Production Management, Vol. 24 Issue: 10, pp.1079-1080.

Noya, L.I., Vasilaki, V., Stojceska, V., Gonzalez-García, S., Kleynhans, C., Tassou, S., Moreira, M.T. and Katsou, E. (2018), “An environmental evaluation of FSC using life cycle assessment: A case study on gluten free biscuit products", Journal of Cleaner Production, Vol. 170, pp.451-461.

OECD. (2019), "Greenhouse Gases", available at OECD database: https://stats.oecd.org/Index.aspx?DataSetCode=AIR_GHG\# (accessed June 17, 2019).

Office for National Statistics. (2017), "Final UK greenhouse gas emissions national statistics: 1990-2014", available at: https://www.gov.uk/government/statistics/final-uk-greenhouse-gas-emissions-nationalstatistics-1990-2014 (accessed August 11, 2017).

Oglethorpe, D. and Heron, G. (2013), "Testing the theory of constraints in UK local food supply chains", International journal of Operations \& Production management, Vol. 33 No. 10, pp.1346-1367.

Parson, D. (2013), "Pinch points affecting the food supply chain", Cranfield University: United Kingdom

Poore, J. and Nemecek, T. (2018), "Reducing food's environmental impacts through producers and consumers", Science, Vol. 360 No. 6392, pp.987-992

Porter, S.D., Reay, D.S., Bomberg, E. and Higgins, P. (2018), "Avoidable food losses and associated production-phase greenhouse gas emissions arising from application of cosmetic standards to fresh fruit and vegetables in Europe and the UK", Journal of Cleaner Production, Vol. 201, pp.869-878.

Pretty, J.N., Ball, A.S., Lang, T. and Morison, J.I. (2005), "Farm costs and food miles: An assessment of the full cost of the UK weekly food basket", Food policy, Vol. 30 No. 1, pp.1-19.

Pullman, M. and Wikoff, R. (2017), "Institutional sustainable purchasing priorities: Stakeholder perceptions vs environmental reality", International Journal of Operations \& Production Management, Vol. 37 No. 2 , pp.162-181.

Ramanathan, U., Bentley, Y. and Pang, G. (2014), "The role of collaboration in the UK green supply chains: an exploratory study of the perspectives of suppliers, logistics and retailers", Journal of Cleaner Production, Vol. 70, pp.231-241.

Röös, E., Sundberg, C., Tidåker, P., Strid, I. and Hansson, P.A. (2013), "Can carbon footprint serve as an indicator of the environmental impact of meat production?", Ecological Indicators, Vol. 24, pp.573-581.

Sanchez-Rodrigues, V., Beresford, A.K.C., Pettit, S.J., Battacharya, S., Harris, I. (2014), "Assessing the cost and CO2emissions impacts of rerouting UK import containers", Transport. Res. Part A: Policy Practice Vol. 61, 53-67.

Saunders, C.M. and Hayes, P., 2007. "Air freight transport of fresh fruit and vegetables".

Saunders, C.M., Barber, A. and Taylor, G.J. (2006), "Food miles-comparative energy/emissions performance of New Zealand's agriculture industry".

Scarborough, P., Appleby, P.N., Mizdrak, A., Briggs, A.D., Travis, R.C., Bradbury, K.E. and Key, T.J. (2014), "Dietary greenhouse gas emissions of meat-eaters, fish-eaters, vegetarians and vegans in the UK. Climatic change", Vol. 125 No. 2, pp.179-192.

Schahczenski, J. and Hill, H. (2009), Agriculture, climate change and carbon sequestration (pp. 14-18). Melbourne: ATTRA.

Schoenherr, T., Narasimhan, R. and Bandyopadhyay, P. (2015), "The assurance of food safety in supply chains via relational networking: a social network perspective", International Journal of Operations \& Production Management, Vol. 35 No. 12, pp.1662-1687.

Smith, P., Martino, D., Cai, Z., Gwary, D., Janzen, H., Kumar, P., McCarl, B., Ogle, S., O’Mara, F., Rice, C. and Scholes, B. (2007), "Policy and technological constraints to implementation of greenhouse gas mitigation options in agriculture", Agriculture, Ecosystems \& Environment, Vol. 118 No. 1, pp.6-28.

Song, J. and Chen, X. (2019), "Eco-efficiency of grain production in China based on water footprints: A stochastic frontier approach". Journal of Cleaner Production, Vol. 236, p.117685

Sundarakani, B., De Souza, R., Goh, M., Wagner, S.M. and Manikandan, S. (2010), "Modeling carbon footprints across the supply chain", International Journal of Production Economics, Vol. 128 No. 1, pp.43-50.

Sustainable Development Commission. (2012), "Looking Back, Looking Forward: Sustainability and UK food policy (2000-2011)", available at: http://www.sd-

commission.org.uk/data/files/publications/FoodPolicy10_Report_final_w.pdf (February 12, 2019)

Tassou, S.A., Kolokotroni, M., Gowreesunker, B., Stojceska, V., Azapagic, A., Fryer, P. and Bakalis, S. (2014), "Energy demand and reduction opportunities in the UK food chain", Proceedings of the Institution of Civil Engineers-Energy, Vol. 167 No. 3, pp.162-170.

Thomsen, A., Sandager, R., Logerman, A., Johanson, J.S. and Andreson, S.A. (2010), "Introduction to EViews 6.0", Analytics Group.

Thornley, P., Gilbert, P., Shackley, S. and Hammond, J. (2015), "Maximizing the greenhouse gas reductions from biomass: The role of life cycle assessment", Biomass and bioenergy, Vol. 81, pp.35-43. 
Tilman, D., Balzer, C., Hill, J. and Befort, B.L. (2011), "Global food demand and the sustainable intensification of agriculture", Proceedings of the National Academy of Sciences, Vol. 108 No. 50, pp.20260-20264.

Toka, A., Koh, S.L. and Shi, V.G. (2015), "Carbon Footprint Management for Food Supply Chains: An Integrated Decision Support System", Supply Chain Management for Sustainable Food Networks, pp.205-231.

UK Trade Experimental Statistics, Office for National Statistics., 2018. Trade in goods, country-bycommodity imports: 2011 to 2016. Available at: ONS Database [Accessed March 07, 2020].

UNL (2017), "Storing Fruits and Vegetables", available at: http://food.unl.edu/documents/storing_fruits_and_vegetables_3.pdf (accessed August 13, 2017).

Vitali, A., Grossi, G., Martino, G., Bernabucci, U., Nardone, A. and Lacetera, N. (2018), "Carbon footprint of organic beef meat from farm to fork: a case study of short supply chain", Journal of the Science of Food and Agriculture, Vol. 98 No. 14, pp.5518-5524.

Wakeland, W., Cholette, S. and Venkat, K. (2012), "Food transportation issues and reducing carbon footprint", In Green Technologies in Food Production and Processing (pp. 211-236). Springer US.

Watkiss, P. (2005), "The validity of Food Miles as Indicators of Sustainable Development and World Ecology", AEA Technology Environment: Oxon, UK.

Xue-gong, L. (2007), "The Precondition and Logistical Model Choice for Fresh Farm Goods Available in Supermarket — With the Case of Shouguang Vegetable Industry in Shandong as Analytical Perspective", Journal of Beijing Technology and Business University (Social Science), Vol. 3, p.002. 


\section{Key factors of Carbon footprint in the UK food supply chains: A new perspective of life cycle assessment \\ Response to reviewers' comments}

\section{Reviewer: 1}

Recommendation: Minor Revision

Comments:

IJOPM-0 6-2019-0478

Reducing UK's Carbon Footprint in Food Supply Chains

This paper uses existing Carbon Footprint Data from countries exporting to the UK (Fruit and Vegetables) to determine the key factors in the supply chain that are driving or reducing emissions. Having worked with food and carbon footprint analysis, I know how challenging it is to get good numbers for this work. Rather than calculated $\mathrm{CO} 2$ emissions for each kind of fruit and vegetable supply chain from various exporters to the UK, the authors instead use a representative sample of specific fruit and vegetable items from key export countries for their analysis. They then apply Multilinear Regression analysis and Stochastic Frontier Analysis to determine the average effects of various activities in the supply chain. Overall, this is a well done study and makes a contribution not only in terms of method but additionally in terms of looking at the issues around continuing to import and a large proportion of the U.K.'s fruit and vegetables from other countries which is clearly a problematic issue not only in the U.K. But also for many countries around the world that rely on imports more than within country production like the U.S. and Japan. Also China is increasing its imports of many food products which isn't really reflected in the time period of this study.

So, while I think the paper is generally in very good shape. I have suggestions for improving the paper that would make it more acceptable for publication. Most of these comments are for clarifications so the paper is more understandable to those readers who do not work with $\mathrm{CO} 2$ emissions and footprint analysis.

\section{Response:}

We would like to thank this reviewer for positive and constructive comments. We appreciate the suggestions made by this reviewer. We have tried to accommodate all the suggestions and feedback from this reviewer in our new modified version of the article. The current version of the paper enhanced with all possible suggestions and it is thoroughly proof-read to ensure a high level of readability.

First, the introduction and literature review areas are fine (see specific grammatical or clarification of sentences issues following the main review.

Response:

We would like to thank this reviewer for acknowledging our work in the introduction and literature review. We have done a thorough proof-reading with support of a native speaker.

I had to read through the paper a few times to understand why the particular methodology was used to connect stages of the supply chain to the overall $\mathrm{CO} 2$ emissions. Because of this methodology, several issues end up being neglected such as food waste, packaging, etc. As a result, it would be important to spend more time in the front end of the methodology section explaining why you had to use this approach (regression and stochastic frontier analysis) and also cite the papers that have also used this approach.

Response: We do agree that the methodology section can be strengthened. In the revised article we have included a new paragraph on the methodologies to highlight specific methods that we 
used in the article, namely regression and stochastic frontier analysis, and their importance in data analysis and results. See the first paragraph in page 6, before section 3.1 (under methodology and conceptualisation section), we have included the rationale of choosing regression and stochastic frontier analysis and also referred a few relevant articles that have followed such approaches. Please note, linear programming method is modified to multivariate approaches in our research.

We agree and appreciate the views of the reviewer on inclusion of issues associated with the supply chain such as food waste, packaging and energy use for machines. As we have limited data on global supply chain emissions from online sources, we tried to make a strong explorative data analysis with the available data on land usage, storage, transportation and distribution. Choosing multivariate data analysis approaches (such as regression and stochastic frontier analysis) helped us to explore and make sense of sample data in hand. With such approaches we were able to study the available data to determine the patterns and test hypotheses (the conceptual framework of key factors of $\mathrm{CO} 2 \mathrm{e}$ ) for circumstantial evidences.

As you can see from the dearth of articles on carbon footprint it in IJOPM, the journal has struggled to include papers on this subject so do a solid job explaining how this method differs from other LCA type of studies and why it is appropriate in this particular case.

\section{Response:}

We appreciate this reviewer's observation of our research distinctive contributions to IJOPM. We have revised the article to accommodate this important suggestion.

See page 3 second paragraph (before Research Questions), we have revised the paragraph to reflect this change.

Second, I found it hard to believe that animal product imports are not generating more $\mathrm{CO} 2$ than fruit and vegetables. Can you include a table that shows estimates of the different food categories to support why you chose to use fruit and vegetables?

\section{Response:}

We agree that animal product imports generate significant CO2e in the food supply chain. It is important to note that our study is focused on fresh fruits and vegetables. To provide clarity and insights into fruits and vegetables CO2e compared to different food categories, we have included a new table in page -2 .

Page 2, Table I shows greenhouse gases emissions (mainly CO2e) associated with food categories production and typical western diet.

In addition, page 2 first paragraph of the revised version provides a detail explanation for our choice of fruits and vegetables supply chain compared to other food categories.

To reflect inclusion of the Table I, we modified the numbering of the tables in the modified version of the article. The current version of the paper is enhanced with appropriately numbered tables and figures.

Third, the discussion (contribution, limitations and opportunities for future research) could be expanded; it seems to have been neglected relative to the rest of the paper. For example, many other countries could benefit from this kind of analysis and one could use other big food categories to see how they might be different from produce. Also, certain aspects have been neglected in this study as you mention (food waste, packaging, etc.). So how might you get at this area? Some fruit and vegetables are more subject to perishability, damage, and waste (for example, only part of the whole item is actually edible) and tropical fruits are one of most popular import items yet have lots of waste elements. The amount of waste in a specific category could be significantly more for a banana versus a locally produced apple. Waste dramatically increases the net $\mathrm{CO} 2$ emissions from particular items. So future research really 
needs to address some of these neglected issues. Also, please think of other implications not only for businesses but for government policy since these are key areas for contributions. Finally, end by stressing the contributions of the paper and a conclusion paragraph.

Response:

We appreciate the reviewer for his/her positive comments on expanding the discussion section of this paper. The following modifications have been made to incorporate the suggestion from the reviewer.

Page 1 of the modified version - practical implications incorporated policy implications and adaptation of efficient energy. Page 16, Section 5.2, has new paragraph on how policies and government regulations in other countries can make positive impacts in their food trade and promote local production.

As correctly pointed by the reviewer, food waste was not captured in the study. However, future researchers can consider assessment of specific category of food waste from different regions. Section 6 is now having a separate heading on limitations and research opportunities.

\section{Details}

Pg. 1, line 60: What do you mean by widely displaced overseas?

Response:

We have revised the sentence to correct the grammatical error. See page 2, the last phrase has been revised to "generated from overseas operations".

This modification also reflected in similar phrase used in page 6 in the Table II.

Pg. 2, line 38: followed by a review of

Pg. 2, line 38: This is the first place that we learn that you will only focus on fruit and veg, can you introduce this early and state why this is a particularly important area? (Note: this is not just for the UK, but many many counties suffer from high $\mathrm{CO} 2$ emissions from that same kind of imports, essentially the developed world are importing fruit and veg from the developing world).

Response:

We thank this reviewer for this observation. See page 2 first paragraph, we have made modification to accommodate this suggestion, particularly introducing the focus of the study and why fruits and vegetables import study is an important area of research.

Pg. 3, line 38: Here you start the line indicating the upcoming material is more recent, but in fact 2012 is not that recent. Can you find more recent citations? If not, I would suggest changing the wording.

Response:

We thank this reviewer for the excellent observation. We have changed the sentence in page 3. We have thoroughly proof-read the article to enhance readability.

Pg. 9, section 3.3: The formatting of all the equations doesn't look right. Perhaps it was the conversation to a pdf but consider creating more space around the equations and lining them up better for clarity.

Response:

We thank this reviewer for the keen observation. Yes, we agree that equations 1 and 2 are not properly formatted on the pdf. We have improved the line spaces and justification to prove better formatting. We are happy to make any further changes in the formatting at the time of printing, if required. For example, we can give equations in jpeg format or Latex.

Please see pages 10 and 11 in the revised version. All four equations are provided as separate equations with adequate line spacing. 


$$
\begin{aligned}
& \operatorname{lnCO_{2}}=\beta_{0}+\ln G F+\operatorname{lnILUK}+\operatorname{lnTRANSPORTATION}+\ln S D \\
& +\epsilon_{i}
\end{aligned}
$$

Pg. 10, line 16: The growers field data would be another very important to get $\mathrm{CO} 2$ emission data. You should consider how this might be estimated in the future as it was presumed nonsignificant based on poor data (5)?

\section{Response}

We appreciate this reviewer's comment on the need to stress the usefulness of growers' field data. We have provided suggestions at the limitation and research opportunities section (Section 6.2) for future study.

Pg. 10, line 59: The word estimate should be plural here I think. Pg. 11, line 27: Vehicles should be plural here.

\section{Response:}

We thank you for this comment. See page 12, the second paragraph for the revised sentence starting with "Multicollinearity test is carried to remove coefficient estimates that have high dependence....".

See page 12, the last paragraph, the word "vehicle" is accordingly changed to plural.

Now we have thoroughly proof-read the article to avoid such minor errors. We hope that the revised version is free from errors and typos.

Pg. 11, line 50: Soil transport? Is this supposed to be land transport?

Response:

Sorry for this error. It must be sea transport. The revised version is free from this error.

Pg. 11, line 56 and 57: This sentence needs improvement so that the reader can interpret what you are trying to say.

Response:

We have modified this sentence in page 13 as follows:

While some results of this study are consistent in line with the literature (e.g. Cadarso et al.,2010), we also have a few new findings that contribute to the existing literature. First, our results strongly recommend that 'improving Sales and Distribution activities can reduce CO2e in the UK FSC'.

Pg. 14, line 9: This seems like an opportunity to again indicate that use of rail rather than trucking might be more appropriate. 


\section{Response:}

We agree with this reviewer's comment. The use of rail is more environmentally friendly. We have included a sentence to stress the relevance of the use of rail transport instead of trucking.

See page 15, Section 5.1, "Otherwise, using rail transport is more environmentally friendly and also help enhancing sustainable FSC. The rail transport is one of the common choices as it is energy efficient, improves environmental performance and reduces CO2e (Lammgard, 2012)"

Pg. 14, line 27: the phrase maintaining "business greener objectives" doesn't make sense. Can you clarify what you are trying to say here? Something to the effect of continuously improving sustainability performance? Pg. 14, line 25: Should be CO2 emission reduction

Pg. 14, line 37: Inclusion of

Pg. 14, line 39: Should be third parties

Pg. 14, line 44: This needs to be reworded. Are you implying that retailers need to stress the importance of buying organic foods to reduce carbon footprints?

Pg. 14, line 46: By this what? Please spell out what you are talking about.

Pg. 14, Line 55: Can you be clear about what it means to develop novelty?

Pg. 14, line 57: Preface with One might ask "why does the UK...."

Response: We modified the section 5.2 in page 16 to reflect all suggested changes. We have double checked this section to ensure quality.

Pg. 14, bottom of page: Here it would be important to note that many UK products (apples, pears, etc) are significantly less perishable and thus less waste which compounds the $\mathrm{CO} 2$ emissions of importing tropical fruits.

\section{Response:}

We appreciate your suggestion on emphasising on the impact of UK products and import of tropical fruits on CO2e. In the revised version in page 16 before Section 6, we emphasised the point to encourage locally produced food in the UK and innovative measures that spearhead local production, which is more sustainable and significantly less waste.

Pg. 15. Another point that should not be lost is that global warming is increasing the ability of the U.K to grow fruits (i.e. grapes) and potentially other vegetables that have traditionally been imported.

Response:

We addressed this comment in Page 16, paragraph 5 (before Section 6). "Though global warming could be affecting UK local production of fruits in the UK, innovative measures and practices can be implemented..."

Pg. 15, line 19: This beginning sentence does not make sense. It is probably missing some words.

Response: The revised version has incorporated changes.

Pg. 15, line 23: "Maintaining greener objectives" means what?

Response:

This is modified in the revised version as 'maintaining environmentally sustainable business objectives' (see page 16, section 5.2) 
Pg. 15, line 29-31: This paragraph needs to be clarified and expanded. Also, please add a conclusion paragraph.

Response:

We thank you for this comment. The revised version has Section 6 Conclusions, Section 6.1. Key contributions and section 6.2 Limitations and research opportunities

Additional Questions:

1. Originality: Does the paper contain new and significant information adequate to justify publication?: Yes, the paper does a nice job at looking at the fruit and vegetable supply chain importation issues ranted to $\mathrm{CO} 2$ emissions with an interesting empirical approach.

Response:

We would like to thank this reviewer for the encouraging comments.

2. Relationship to Literature: Does the paper demonstrate an adequate understanding of the relevant literature in the field and cite an appropriate range of literature sources? Is any significant work ignored?: As far as I can tell, the authors have used appropriate literature to support their study. In a couple instances, I have asked for more current citations.

Response:

We would like to thank this reviewer for the positive and constructive comments. We appreciate the suggestions made by this reviewer and we have made all relevant modifications. The current version of the paper is thoroughly proof-read with support of a native speaker.

3. Methodology: Is the paper's argument built on an appropriate base of theory, concepts or other ideas? Has the research or equivalent intellectual work on which the paper is based been well designed? Are the methods employed appropriate?: The paper has an appropriate methodology but I have suggested that the authors spend more time justifying why they used their approach rather than a more detailed LCA analysis of specific (biggest volume) fruit and vegetables imported into the UK.

Response:

We thank this reviewer for the encouraging and constructive comments. We appreciate the suggestions made by this reviewer. We have clarified the methodological approaches used. The current version of the article communicates better justification of the methodology and its contribution to the literature and the journal.

4. Results: Are results presented clearly and analysed appropriately? Do the conclusions adequately tie together the other elements of the paper?: The results are very clear and the tables/figures support the text. The conclusion section seems to have received the least amount of attention, so the authors need to work on expanding the discussion, limitations, and conclusion.

\section{Response:}

We are grateful for this reviewer's encouraging comment on the results and presentation of the tables/figures. We have accommodated all the suggestions on the conclusion section and appropriate expansion and modification are incorporated. The current version of the paper enhanced with all possible suggestions (on the discussion, limitations, and conclusion) and it is thoroughly proof-read.

5. Implications for research, practice and/or society: Does the paper identify clearly any implications for research, practice and/or society? Does the paper bridge the gap between theory and practice? How can the research be used in practice (economic and commercial impact), in teaching, to influence public policy, in research (contributing to the body of 
knowledge)? What is the impact upon society (influencing public attitudes, affecting quality of life)? Are these implications consistent with the findings and conclusions of the paper?: This section should be expanded more. There are many implications for improving not only business but government policies that would support the use of better transportation mechanisms and infrastructure to continuously reduce the emissions from food trade.

\title{
Response:
}

We appreciate the excellent observation of this reviewer. We have tried to accommodate all the suggestions and feedback from this reviewer in our new modified version. The current version is expanded and enhanced with all relevant implications for improving government infrastructure and transportation policies that can massively reduce carbon emissions along supply chains.

\section{See pages 15-16, Section 5.2 Policy and legal-related measures}

6. Quality of Communication: Does the paper clearly express its case, measured against the technical language of the fields and the expected knowledge of the journal's readership? Has attention been paid to the clarity of expression and readability, such as sentence structure, jargon use, acronyms, etc.: The paper has a number of unclear sentences and incorrect word use/grammatical errors. I have indicated the areas where I see issues but it would help to do a solid edit before submitting the paper again.

\section{Response:}

We are grateful for the reviewer's comments. We also proof-read the article thoroughly with support of a native speaker.

\begin{abstract}
Reviewer:2
Recommendation: Major Revision

Comments:

Dear authors, first of all, thank you for the opportunity of reading your manuscript 'Reducing UK's Carbon footprint in food supply chains'. Indeed, food supply chains generate considerable impacts on the environment. Learning from the UK case adds to the current body of knowledge. As I see merit in your research, I also feel the manuscript can be developed further, mainly in terms of the organisational theories capable of supporting your analysis, and in terms of the real originality of your work. I hope you will find my comments useful in order to achieve an improved version of your manuscript.

Response:

We thank this reviewer for his/her encouraging words. We have tried to accommodate all the suggestions and feedback from this reviewer to develop the manuscript. The current version of the paper has enhanced quality by incorporating most of the suggestions and feedback from the reviewers. We have also proof-read the article thoroughly with support of a native speaker.
\end{abstract}

\section{GENERAL SUGGESTIONS:}

- the manuscript does not have any organisational theory as supporting theory. Would it be relevant to have it?

- research results cover a period of secondary data from 1990-2014, which is quite in the past. It should be justified and added as limitation. This is not a flaw if recognised as limitation, but I concerned.

- latest references are missing. It seems like the paper was produced around 2014/15. This is not wrong, but please consider latest references from IJOPM and top sustainability journals 
- Have you identified 'factors' of supply chains or 'activities' of supply chains? Also, you have not covered all food supply chain of the UK, but a fraction of the fruits and vegetables supply chain from selected suppliers. This should be clear from the start

\section{Response:}

We thank this reviewer for the positive feedback and constructive criticism. We made the following modifications to accommodate the suggestions.

This research was conducted in 2017 and we used the data available at that time. Some of the data was not complete and hence we were forced to omit those data. This is one of the limitations of this study. However, we have wisely used the available dataset to arrive at managerial decision making on sustainably related issues. We have included further explanation in a new section 6.2 in page 17.

We have included a few latest articles in relation to our topic of research from IJOPM and also from other journals such as IJPR. See page 4 second paragraph and page 5 first paragraph. We have highlighted the articles that we considered in the modified version; this is in the reference list in pages $17-22$.

We agree that our paper has not included any theory to support our arguments. It may be ideal to use organisational theories; however, we feel this research on UK Carbon footprint with LCA is somewhat new to business and social sciences and it will need in-depth research to establish a strong theory to create a sustainable approach in reducing $\mathrm{CO} 2 \mathrm{e}$ in Food supply chains. Using some of the established theories of operations management such as resourcebased view and stakeholders' theory may help to relate available resources efficiently to reduce $\mathrm{CO} 2 \mathrm{e}$ and also help to involve the import/export businesses to control carbon emissions through strict measures. We will consider this in our future work. This is further explained in the limitations in section 6.2.

1) TITLE: The current title is a bit misleading, because when you use the term 'reducing' in 'Reducing UK's Carbon footprint in food supply chain' it seems that your manuscript will explore how companies in the food supply chain did reduce their emissions. However, your paper is much more about identifying key elements in the UK food supply chain, is not it? In this context, I would suggest the following title: 'Identification of key factors of carbon emissions in food supply chains in the United Kingdom: life cycle assessment perspective' or something similar to this.

Response:

We have considered this suggestion and modified the title as follows: Key factors of Carbon footprint in the UK food supply chains: A new perspective of life cycle assessment

2) ABSTRACT: you use secondary data obtained from ONS and FAOSTAT. However, what is the timeline of the data set you have?

Response:

We have made changes in the abstract to reflect this suggestion. The timeline for the dataset 1990-2014 is included. We also explained this further in the page 6 under Section 3.

3) ABSTRACT and the entire text: can you really affirm 'Transportation and Sales/Distribution are the two key factors'? I mean, are 'transportation' and 'sales/distribution' really 'factors' or are they operations management activities? Please, think about it.

Response:

We thank this reviewer for this comment. Our conceptual framework first captured all activities within the food supply chains of the overseas countries who export to the UK. Following extant literature review, we noted the activates among others include land use, synthetic fertilisers 
use, application of manure, organic soil farming, burning of crop residues, on-farm transportation, overseas storage, port logistics, road transport, sea transport, air transport, rail transport, delivery, storage and distribution. To enhance implementation of sustainable policies and measures within specific areas of the food supply chains, we grouped all the activities into areas of operations and supply chain management activities which we refer to as the "key factors". Thus, Growers field, Inland logistics, Transportation and Sales and Distribution were considered for this study.

Page 3, para -2 reflects the changes made in the revised version.

4) ABSTRACT and Introduction: Regarding originality, we know that LCA is a new tool in operations management, however, in environmental sciences, it a consolidated tool. For example, journals such as International Journal of Life Cycle Assessment, Journal of Cleaner Production, among others, publish dozens of papers applying LCA to production chains. In this context, please, highlight the uniqueness of your paper. It is well known that transportation logistics is very much responsible for considerable amount of $\mathrm{CO} 2$ emissions. But I am sure your research has something unusual, unique, different from others to be highlighted.

Response:

We thank this reviewer for the constructive comments. A new section 6.1 in page 17 included contributions of this study.

5) KEYWORDS: I would like to suggest 'low carbon operations' and 'low carbon economy' as potential keywords

Response:

We thank you for this comment. 'Low carbon operations' is added as one of the key words.

6) INTRODUCTION: Once again, the objective of the paper is to understand 'factors' while I very much believe that you have understood 'operations and supply chains activities' which generate more $\mathrm{CO} 2$. Is this 'factors' or 'activities'?

Response:

We thank the reviewer for the excellent observation and positive comment. We have provided clarity on the "factors" and "activities" presented in the paper and how they are related with operations and supply chain activities.

See modifications in page 3, para -1 .

7) INTRODUCTION: this sentence would benefit from references/citations: 'Drawing from existing studies...'

Response:

We thank you for this comment. We have made modification that provide in-text citations. See page 3 third paragraph for the changes.

"Drawing from existing studies (Pretty et al., 2005; Smith et al., 2007), a conceptual framework is developed to enable identification of all the stages of FSC from outside (exporting countries) to the UK."

8) RESEARCH RESULTS: I really see value in this result 'SFA results confirm that the key factors are sufficient to predict an increase or decrease in $\mathrm{CO} 2$ emissions in the UK food supply chains.' I would suggest putting it as one of the main contributions of your work Response:

We thank you for this positive and encouraging comment. We have made the following modifications:

In page 1, in the abstract, we have highlighted this "In addition, the SFA results confirm that the key factors are sufficient to predict an increase or decrease in $\mathrm{CO} 2$ emissions in the UK food supply chains." 
Page 14, Section 4.3, we have included the changes as follows: "This implies that the key factors are technically efficient to determine an increase or decrease of the CO2e in UK FSC (the output variable)."

Page 16, Section 6, has reflected the changes as follows: "Additionally, SFA results confirm that the key factors are sufficient to predict an increase or decrease in $\mathrm{CO} 2$ emissions in the UK food supply chains. This paper contributes to the existing literature..."

9) Literature review is not update. There are policy documents and reports that are quite new, but in terms of academic literature, authors could add latest papers. I will mention some of them:

https://eur03.safelinks.protection.outlook.com/?url=https\%3A\%2F\%2Fdoi.org\%2F $10.1002 \%$ 2Fbse.1832\&amp; data $=01 \% 7 \mathrm{C} 01 \% 7$ Cusha.ramanathan\%40ntu.ac.uk\%7C9132ac198f13488c 277308d7bc8817c9\%7C8acbc2c5c8ed42c78169ba438a0dbe2f\%7C0\&amp;sdata=nAaOgd8c bB7hmO9qX2aU60yrDYc3KkpyvllV\%2Fw9MV1I\%3D\&amp;reserved $=0$

https://eur03.safelinks.protection.outlook.com/?url=https $\% 3 \mathrm{~A} \% 2 \mathrm{~F} \% 2 \mathrm{Fdoi}$. org $\% 2 \mathrm{~F} 10.1080 \%$ 2F00207543.2017.1421790\&amp; data $=01 \% 7 \mathrm{C} 01 \% 7 \mathrm{Cusha}$.ramanathan\%40ntu.ac.uk\%7C91 32ac198f13488c277308d7bc8817c9\%7C8acbc2c5c8ed42c78169ba438a0dbe2f\%7C0\&amp;s data $=$ eOfcxq9v7GYj3QXvmbItI0Wv1qiZjNSHKAggSbox7Bk\%3D\&amp;reserved $=0$

\section{Response:}

We have read and included the review article (de Sousa Jabbour et al., 2019) as suggested by this reviewer in the modified version. We have also included a few more new articles to add value to our research work. Now our review is up to 2019 and this includes a rich academic literature such as Schoenherr et al. (2015), Pullman and Wikoff (2017), Poore and Nemecek (2018), Porter et al. (2018) and Hendry et al. (2019).

See page 4 and page 5 for some of the latest journals included to accommodate this suggestion. We also have a number of current top journals included throughout the article in the modified version. We believe that the revised version is updated with the latest literature.

10) SECTION 2.1: The figures/facts/numbers about waste in food supply chains are quite outdate. You bring data from 2014, 2015, and I was wondering if you could please add something more recent.

\section{Response:}

Revised version of the paper has included more recent facts and figures throughout the article. We do understand the importance of using recent data, but we had limitation when this research was conducted in 2017 and we used the data available at that time. Some of the data was not complete and hence we were forced to omit those data. This is one of the limitations of this study. However, we have wisely used the available dataset to arrive at managerial decision making on sustainably related issues. We have included further explanation in the new section 6.2, page 17 .

11) SECTION 3.1: At this stage, it is clear that your work does not use any organisational theory - such as the stakeholders' theory - or ecological modernisation - to support your theoretical/framework choices. While this is not a flaw of your paper, my understanding is that IJOPM is journal, which aims to develop theory further. Please think about it... would it be a limitation of your research?

Response:

We thank the reviewer for this comment. We address this as one of the main limitations of the paper. See page 17, section 6.2 (limitations and research opportunities). We suggest that further study can extend the paper and help develop theoretical contributions and insights into different 
organisational theories such as ecological modernisation theory and resource-based view theory.

12) SECTION 3.2: It is surprising that your data refers to 'secondary data collected from FAOSTAT (2017) and ONS (2017) covering 1990 to 2014'. Anyway, data is quite old, and it should be provided clear justification and limitation. Indeed, if the manuscript is published in 2020/2021, research results will be quite old.

Response:

We thank this reviewer for this observation and comment. Data was capped to 2014 due to large amount of missing data for most countries and the activities for 2015 to 2019 was not complete. Microdata of this kind take longer time for researchers e.g. FAO to update to current years. However, we address this as a limitation of the paper. See page 17, section 6.2 (limitations and research opportunities).

13) SECTION 5: implications for theory, practitioners, and policy makers are too general. It would be great if authors create subsections for each beneficiary of this paper. Also, a clear section about limitations should be provided. This paper has significant implications for supply chain and logistics managers, and thus lessons learned for these professionals could be added. Most of the countries that supply to the UK food sector (as per your research) are from emerging economies. Any specific implication/guideline for them?

I hope authors will find comments useful, and I thus suggest that the manuscript could be revised before publication. Good luck!

Response:

We thank this reviewer for the constructive and positive comments. We have tried to accommodate all suggestions in the modified version. We have added a new section for policy and legal-related measures, please see Section 5.2, page-15 and 16.

"Second, logistics and supply chains managers from emerging economies can integrate lowcarbon policies and practices into their operations which could become the organisation's competitive advantage while contributing to more sustainable society. Integrating low-carbon polices and measures involve planning, implementation and maintaining carbon efficiency of business activities and processes. The practices should entail low-carbon products, low-carbon production and low-carbon logistics (de Sousa Jabbour et al., 2019)".

Additional Questions:

1. Originality: Does the paper contain new and significant information adequate to justify publication?: Please, see detailed comments in 'Comments to the Authors'. I am concerned that used secondary data covers from 1990 to 2014.

Response:

We thank the reviewer for this comment. We have responded to this comment earlier. We have provided appropriate modifications in the paper.

2. Relationship to Literature: Does the paper demonstrate an adequate understanding of the relevant literature in the field and cite an appropriate range of literature sources? Is any significant work ignored?: A number of latest references in low carbon operations are not cited. Please update them. Please, see detailed comments in 'Comments to the Authors'.

\section{Response:}

We have modified the article in line with this comment. We have a number of current top journals included throughout the modifications. For example, de Sousa Jabbour et al. (2019) from International Journal of Production Research. Please see page 18-22. 
3. Methodology: Is the paper's argument built on an appropriate base of theory, concepts or other ideas? Has the research or equivalent intellectual work on which the paper is based been well designed? Are the methods employed appropriate?: There is no clear organisational theory used as supporting theory. Please, see detailed comments in 'Comments to the Authors'.

\section{Response:}

We have provided further justification and clarity for methodological approaches used for this research in page 6 under Section 3. We also addressed missing organisational theories as limitation of the research and provided suggestions for future study, in page -17 under Section 6.2 .

4. Results: Are results presented clearly and analysed appropriately? Do the conclusions adequately tie together the other elements of the paper?: Yes, they are. Please, see detailed comments in 'Comments to the Authors'.

\section{Response:}

We thank the reviewer for this encouraging comment. We have addressed all concerns related to this comment. We have included new sub-sections under Section 6. Section 6.1 Key contributions and Section 6.2 Limitations and research opportunities.

5. Implications for research, practice and/or society: Does the paper identify clearly any implications for research, practice and/or society? Does the paper bridge the gap between theory and practice? How can the research be used in practice (economic and commercial impact), in teaching, to influence public policy, in research (contributing to the body of knowledge)? What is the impact upon society (influencing public attitudes, affecting quality of life)? Are these implications consistent with the findings and conclusions of the paper?: It can be improved further. Please, see detailed comments in 'Comments to the Authors'.

\section{Response:}

The current version of the paper is enhanced with expanded implications for research and practice. We have responded to these comments in the previous questions.

6. Quality of Communication: Does the paper clearly express its case, measured against the technical language of the fields and the expected knowledge of the journal's readership? Has attention been paid to the clarity of expression and readability, such as sentence structure, jargon use, acronyms, etc.: Please, sometimes there is overusing of acronyms in abstract and title.

\section{Response:}

We thank this reviewer for his/her positive and constructive comments. The current version of the paper has been thoroughly proof-read to ensure its language and structure. 


\section{Key factors of Carbon footprint in the UK food supply chains: A new perspective of life cycle assessment}

Table I. GHG emissions (in CO2e) associated with food categories production and typical western diet

\begin{tabular}{|c|c|c|c|}
\hline \multicolumn{2}{|c|}{$\begin{array}{l}\text { Greenhouse gas (GHG) emissions for food } \\
\text { categories production (weighted) in the } \\
\text { UK including import from EU and outside } \\
\text { EU }\end{array}$} & \multicolumn{2}{|c|}{$\begin{array}{l}\text { Contribution of different food categories to } \\
\text { diet-related GHG emissions (CO2e) }\end{array}$} \\
\hline 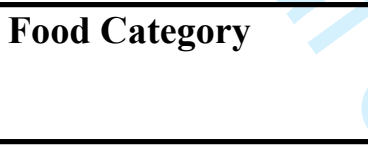 & $\begin{array}{l}\text { GHG emissions } \\
\text { (kgCO2e/kg) }\end{array}$ & Food Category & $\begin{array}{l}\text { Per cent of GHG } \\
\text { emissions }(\mathrm{CO} 2 \mathrm{e}) \text { in } \\
\text { typical western diet }\end{array}$ \\
\hline Meat & 35.9 & $\begin{array}{l}\text { Meat, Beans, Fish, } \\
\text { and Other non-dairy } \\
\text { proteins }\end{array}$ & 57 \\
\hline Fruits and Vegetables & 1.6 & Fruits and Vegetables & 11 \\
\hline Milk & 1.8 & Milk and Diary & 14 \\
\hline Poultry Meat & 5.4 & $\begin{array}{l}\text { Bread, Potato, Pasta, } \\
\text { Rice and Other starchy } \\
\text { foods }\end{array}$ & 6 \\
\hline Rice & 3.9 & $\begin{array}{l}\text { Food and Drinks } \\
\text { (High in Sugar and/or } \\
\text { Fat) }\end{array}$ & 5 \\
\hline Fish & 5.4 & $\begin{array}{l}\text { Other Miscellaneous } \\
\text { Foods e.g., Alcohol, } \\
\text { Sources and Hot } \\
\text { drinks }\end{array}$ & 7 \\
\hline Tea & 1.9 & & \\
\hline Wheat/Oats & 1.0 & & \\
\hline Sugar & 0.1 & & \\
\hline
\end{tabular}


Table II. Studies on activities of UK food supply chains and its related CO2e implications.

\begin{tabular}{ll}
\hline Study & Findings \\
\hline Jones (2002) & $\begin{array}{l}\mathrm{CO}_{2} \mathrm{e} \text { associated with supply of fresh food to the UK consumers } \\
\text { transported by trucks or planes is greater than rail. }\end{array}$ \\
\hline Marriott (2005) & $\begin{array}{l}\text { Significant portion of } \mathrm{CO}_{2} \mathrm{e} \text { is associated with fresh food import from } \\
\text { EU and non-EU countries. Majority of this } \mathrm{CO}_{2} \mathrm{e} \text { is caused by food } \\
\text { transport. }\end{array}$ \\
\hline Garnett (2006) & $\begin{array}{l}\mathrm{CO}_{2} \mathrm{e} \text { are generated throughout the life cycle hotspots of FSC. The } \\
\text { hotspots include transportation, storage and waste. }\end{array}$ \\
\hline Saunders et al. (2006) & $\begin{array}{l}\mathrm{CO}_{2} \mathrm{e} \text { per tonne of apples produced in the UK are higher than in the New } \\
\text { Zealand due to higher use of energy. }\end{array}$ \\
\hline McKinnon and Piecyk (2012) & $\begin{array}{l}\text { Significant amount of } \mathrm{CO}_{2} \mathrm{e} \text { produced from transport operations. } \\
\text { Hulthén and Gadde (2009) }\end{array}$ \\
$\begin{array}{l}\text { Modified distribution facilities (e.g., trucks and distribution centres) } \\
\text { efficiently utilised can reduce fuel consumption and CO }\end{array}$ \\
\hline Audsley et al. (2010) & $\begin{array}{l}\text { A significant proportion of } \mathrm{CO}_{2} \mathrm{e} \text { (101 } \mathrm{Mt}_{\mathrm{CO}} \mathrm{CO}_{2} \text {-equivalent emissions) } \\
\text { from global land use change attributable to the UK FSC. }\end{array}$ \\
\hline Garnett (2011) & $\begin{array}{l}\text { FSC produces } \mathrm{CO}_{2} \text {-equivalent emissions at all stages in its life cycle, } \\
\text { starting from the farming process and its inputs, through to } \\
\text { manufacturing, refrigeration, distribution, retailing, food preparation and } \\
\text { waste disposal. Evidence shows that in addition to technological } \\
\text { mitigation, there is need to shift patterns of consumption. }\end{array}$
\end{tabular}

\begin{tabular}{|c|c|}
\hline Defra (2013) & $\begin{array}{l}176 \mathrm{Mt} \text { of } \mathrm{CO}_{2} \text {-equivalent is generated within the UK domestic food } \\
\text { sector in } 2011 \text { and significant amount is generated from food transport. }\end{array}$ \\
\hline Mangalassery et al. (2014) & $\begin{array}{l}\text { Adopting zero tillage systems such as crop residue cover play significant } \\
\text { role in reducing } \mathrm{CO} 2 \mathrm{e} \text {. }\end{array}$ \\
\hline Tassou et al. (2014) & $\begin{array}{l}\text { FSC is responsible for } 176 \mathrm{Mt} \mathrm{CO}_{2} \mathrm{e} \text { emissions while food waste counts } \\
\text { for } 15 \mathrm{Mt} \mathrm{CO} 2 \text { equivalent emissions. } \mathrm{CO}_{2} \mathrm{e} \text { are generated throughout the } \\
\text { FSC, e.g., agriculture, manufacturing, domestic operations, storage, } \\
\text { transport, retail and catering. }\end{array}$ \\
\hline de Ruiter et al. (2016) & $\begin{array}{l}\text { The UK is increasingly reliant on outsourcing countries and the } \mathrm{CO}_{2} \mathrm{e} \\
\text { associated with the FSC is increasingly generated from overseas } \\
\text { operations. }\end{array}$ \\
\hline
\end{tabular}


Table III: Selected Countries, Fruit and Vegetables, Farming Community, Storage Facility Centre, Days of Storage and Ports for Export

\begin{tabular}{|c|c|c|c|c|c|}
\hline Country & $\begin{array}{c}\text { Selected } \\
\text { Fruit and } \\
\text { Vegetables }\end{array}$ & $\begin{array}{c}\text { Selected } \\
\text { Farmland/Farming } \\
\text { Community }\end{array}$ & $\begin{array}{l}\text { Storage Facility } \\
\text { Centres }\end{array}$ & $\begin{array}{l}\text { Days of } \\
\text { Storage }\end{array}$ & Export Centres/Ports \\
\hline China & $\begin{array}{l}\text { Banana } \\
\text { Pepper }\end{array}$ & Guangdong & $\begin{array}{l}\text { Guangdong Fruit, } \\
\text { Vegetable and Non- } \\
\text { staple Food } \\
\text { Company. }\end{array}$ & 3 & $\begin{array}{l}\text { Port of Shenzhen } \\
\text { Guangzhou Baiyun } \\
\text { International Airport, } \\
\text { Guangdong Sheng, } \\
\text { China }\end{array}$ \\
\hline Colombia & $\begin{array}{l}\text { Banana } \\
\text { Pineapple }\end{array}$ & $\begin{array}{l}\text { Colanta SA } \\
\text { company } \\
\text { Farmland, Girón, } \\
\text { Santander, } \\
\text { Colombia }\end{array}$ & $\begin{array}{l}\text { Storage Facility, } \\
\text { Colanta, 66, Girón, } \\
\text { Santander, Colombia }\end{array}$ & 3 & $\begin{array}{l}\text { Barranquilla Port } \\
\text { El Dorado } \\
\text { International Airport }\end{array}$ \\
\hline $\begin{array}{l}\text { Costa } \\
\text { Rica }\end{array}$ & $\begin{array}{l}\text { Melons } \\
\text { Banana }\end{array}$ & Limón Central & $\begin{array}{l}\text { Almacen Villalazo, } \\
\text { Limón, Siquirres, } \\
\text { Costa Rica }\end{array}$ & 3 & $\begin{array}{l}\text { Port of Puerto Limon } \\
\text { Limon International } \\
\text { Airport }\end{array}$ \\
\hline Spain & $\begin{array}{l}\text { Grapes } \\
\text { Lettuce }\end{array}$ & Province of Murcia & $\begin{array}{l}\text { Moving and Storage } \\
\text { La Seda, Mudanzas } \\
\text { y Guardamuebles La } \\
\text { Seda }\end{array}$ & 3 & $\begin{array}{l}\text { Noatum Container } \\
\text { Terminal Valencia, } \\
\text { Port of Madrid } \\
\text { Ciudad Real Airport }\end{array}$ \\
\hline France & $\begin{array}{l}\text { Apple } \\
\text { Tomatoes }\end{array}$ & D'aucy & $\begin{array}{l}\text { D'aucy, Prince de } \\
\text { Bretagne }\end{array}$ & 3 & $\begin{array}{l}\text { Nantes Saint-Nazaire } \\
\text { Port } \\
\text { Lann Bihoue Airport }\end{array}$ \\
\hline Ghana & $\begin{array}{l}\text { Banana } \\
\text { Pineapple }\end{array}$ & $\begin{array}{l}\text { Nyanyano, Kasoa, } \\
\text { Central, Ghana }\end{array}$ & $\begin{array}{l}\text { Jei River Farms } \\
\text { Awutu }\end{array}$ & 3 & $\begin{array}{l}\text { Tema Ports and } \\
\text { Harbours } \\
\text { Kotoka International } \\
\text { Airport, Accra }\end{array}$ \\
\hline India & $\begin{array}{l}\text { Mango } \\
\text { Banana }\end{array}$ & $\begin{array}{l}\text { Sericulture } \\
\text { Maharashtra }\end{array}$ & $\begin{array}{l}\text { Cold Chain Solution } \\
\text { of India }\end{array}$ & 3 & $\begin{array}{l}\text { JSW Jaigart Port } \\
\text { Chhatrapati Shivaji } \\
\text { International Airport }\end{array}$ \\
\hline $\begin{array}{l}\text { South } \\
\text { Africa }\end{array}$ & $\begin{array}{l}\text { Apple } \\
\text { Pears }\end{array}$ & $\begin{array}{l}\text { Elgin, Southern } \\
\text { Africa }\end{array}$ & Interpaarl Logistics & 3 & $\begin{array}{l}\text { Transnet Port } \\
\text { Terminals - Cape } \\
\text { Town } \\
\text { Cape Town } \\
\text { International Airport }\end{array}$ \\
\hline
\end{tabular}

Note: Three (3) days is the estimated days for storage based on the work of UNL (2017) that suggests safe standard for storing fruits and vegetables 
Table IV. Selected Activities of the UK FSC (Input Variables)

\begin{tabular}{lll}
\hline $\begin{array}{l}\text { Variable } \\
\text { (As presented in the model) }\end{array}$ & Description of Variable & $\begin{array}{l}\text { Authors' Calculation and Source of } \\
\text { Data Collection } \\
\text { [multiple sources; but main source: } \\
\end{array}$ \\
& FAOSTAT (2017)]
\end{tabular}

Land use

(Land use)

Synthetic Fertilisers

(SF)

Manure Applied

(MA)

Crop Residues Applied

(CR)

Organic Soil

(OS)

Burning Residues

(BR)

On-farm transportation

(OFT)

Overseas storage

(OVS)

Port logistics

(PL)

Road

(Hdv)

Air

(Plane)

Rail

(Train)
This is the emissions produced by the use of cropland and land use change by the country

This is the emissions produced by the use of synthetic fertilisers in a country for agricultural activities. This is emissions produced by applying manures on agricultural soils by farmers.

This is emissions from crop residues and pasture renewal left on agricultural lands by farmers.

This is emissions from cultivated organic soils under cropland.

This is the emissions produced by the combustion of a portion of crop residues burnt on farming fields.

This is emissions from use of heavy-duty vehicles for transportation of fruits and vegetables from farmland to the overseas storage as a proxy for farm produce logistics.

This is the emissions from storage of fruits and vegetables from overseas at the warehouses before transporting it to the port for export.

This is emissions from the transport of fruits and vegetables from the warehouse to the ports (either the airport or cargo port or train station).

This is emissions from road (heavyduty) transport of fruits and vegetables from home grown country to the UK.

This is emissions from air (plane) transport from fruits and vegetables from home grown country to the UK.

This is emissions from train transport of fruits and vegetables
Calculation based on cropland emissions.

Calculation based on synthetic fertilisers emissions.

Calculation based on manure applied to soils emissions

Calculation based on crop residues on soils.

Calculation based on organic soil cropland emissions.

Calculation based on burning residue emissions.

Calculation based on heavy-duty transport emissions (as a proxy) for fuel and machinery use for transporting fruit and vegetables.

Calculation based on storage emissions provided by Wakeland $e t$ al. (2012) and work of UNL (2017).

Calculation based on distance from the overseas storage and emissions by heavy-duty vehicle transport of the fruits and vegetables.

Calculation based on distance from between the cities (home grown country capital and London, considering the location of the port) and emission by heavy-duty vehicle transport.

Calculation based on the air travel distance from between the cities (home grown country airport nearest to overseas storage and Heathrow airport) and emission by plane transport.

Calculation based on the travel distance from between the cities 
Sea

(Transoceanic)

Delivery

(DV)

Storage for Distribution (SfD)

Distribution (Distr) from home grown country to the UK

This is emissions from sea (transoceanic) transport of fruits and vegetables from home grown country to the UK.

This is emissions from transport of fruits and vegetables from the port by heavy-duty vehicles to warehouses of retailers in the UK.

This is emissions from storage of fruits and vegetables at the warehouse before transported to sales point warehouse.

Emissions from transport of fruits and vegetables from the storage (warehouse) in the UK to the retailer's sale point by heavy-duty vehicles. (home grown country rail station nearest to overseas storage and St. Pancras Station) and emission by train transport.

Calculation based on the travel distance from between the cities (home grown country cargo port station nearest to overseas storage and London Port) and emission by train transport.

Calculation based on the travel distance from the port in London to the retailer's large storage (warehouse) using Tesco Groceries Warehouse (as the storage point) and emission by heavy-duty vehicle transport.

Calculation based on storage emissions provided by Wakeland et al. (2012) and work of UNL (2017).

Calculation based on heavy-duty vehicle transport emissions of the fruit and vegetables from storage (warehouse) in the UK to the retailer's sales point.

Notes: Detail of these calculations can be provided on request. All final values of variables are in tonnes of $\mathrm{CO}_{2} \mathrm{e}$. 
Table V. Key Factor Variables and Dependent Variable

\begin{tabular}{ll}
\hline $\begin{array}{l}\text { Variable } \\
\text { (As presented in the model) }\end{array}$ & Description of Variable \\
\hline $\begin{array}{l}\mathrm{CO} 2 \mathrm{e} \\
\left(\mathrm{CO}_{2}\right)\end{array}$ & $\begin{array}{l}\text { UK Carbon dioxide emissions from all } \\
\text { sectors. }\end{array}$ \\
$\begin{array}{l}\text { Growers' Field } \\
(\mathrm{GF})\end{array}$ & $\begin{array}{l}\text { This is the emissions from the } \\
\text { summation of land use, synthetic } \\
\text { fertilisers, manure applied, crop } \\
\text { residues, organic soil and burning } \\
\text { residues emissions. }\end{array}$ \\
$\begin{array}{ll}\text { Inland Logistics outside the } \\
\text { UK }\end{array}$ & $\begin{array}{l}\text { This is emissions from the summation } \\
\text { on-farm transportation, storage of } \\
\text { fruits and vegetables (in overseas) and } \\
\text { port logistics. }\end{array}$
\end{tabular}

Calculation and Source of Data Collection

Transportation (Transportation)

This is transport emissions of fruits and vegetables from all the selected countries to the UK. It is the sum of variable road, air, rail and sea.

This is the emissions from delivery to retailer's warehouses, storage for distribution and distribution to retailer's shops. It is sum of the variables delivery, storage for distribution and distribution.
Office for National Statistics (2017)

Based on the summation of emissions from land use, synthetic fertilisers, manure applied, crop residues, organic soil and burning residues from FAOSTAT (2017).

Based on the summation of emissions from on-farm transportation, overseas storage and port logistics from FAOSTAT (2017).

Based on the summation of emissions from all modes of transportation particularly by road (heavy-duty vehicles), air (planes), sea and rail. Calculation method adopted from Edwards-Jones et al. (2008) and Elhedhli and Merrick (2012

Author's calculation by addition of Delivery, Storage and Distribution emissions. Calculation method adopted from Edwards-Jones et al. (2008) and Elhedhli and Merrick (2012

Notes: Based on Author's calculation. All final values of variables are in tonnes of $\mathrm{CO}_{2} \mathrm{e}$. 
Table VI. Key Factors of Carbon Dioxide Emissions

1
2
3
4
5
6
7
8
9
10
11
12
13
14
15
16
17
18
19
20
21
22
23
24
25
26
27
28
29
30
31
32
33
34
35
36
37
38
39
40
41
42
43
44
45
46
47
48
49
50
51
52
53
54
55
56
57
58
59
60

\begin{tabular}{lc}
\hline Variable & Coefficient \\
\hline Growers' field & $-0.000(0.001)$ \\
Inland Logistics outside the UK & $0.003(0.004)$ \\
Transportation & $0.100 * *(0.009)$ \\
Sales and Distribution & $-0.013^{* * *}(0.005)$ \\
Summary Statistics: & \\
Observation & 400 \\
R-squared & 0.585 \\
Adjusted R-squared & 0.577 \\
Prob(F-statistic) & 0.007 \\
Notes: $* * * p<0.01, * * p<0.05$ and $*$ p $<0.1$. The standard errors are the values in the parentheses. Prob (F- \\
statistic) showing the overall significant predicative capacity of the model.
\end{tabular}


Table VII. Inputs (Activities) of Key Factors of $\mathrm{CO}_{2} \mathrm{e}$

\begin{tabular}{lc} 
Variable & Coefficient \\
\hline Land use & $0.063^{* * *}(0.020)$ \\
Synthetic Fertilisers & $0.002(0.014)$ \\
Manure Applied & $0.003(0.018)$ \\
Crop Residues Applied & $-0.024^{* *}(0.012)$ \\
Organic Soil & $-0.041^{* *}(0.016)$ \\
Burning Residues & $0.008(0.013)$ \\
On-farm Transportation & $20.553(12.666)$ \\
Overseas Storage & $0.062 * * *(0.016)$ \\
Port Logistics & $-8.208(4.800)$ \\
Road Transport & $0.110^{*}(0.065)$ \\
Rail Transport & $-0.107 * * *(0.066)$ \\
Sea Transport & $0.029 *(0.018)$ \\
Delivery & $-12.444(7.880)$ \\
Storage for Distribution & $0.042 * * *(0.014)$ \\
Distribution & $0.046(0.068)$ \\
Summary Statistics & \\
Observation & \\
R-squared & 400 \\
Adjusted R-squared & 0.631 \\
Prob(F-statistic) & 0.551 \\
Nores & 0.000 \\
\hline
\end{tabular}

Notes: ${ }^{* * *} \mathrm{p}<0.01,{ }^{* *} \mathrm{p}<0.05$ and $* \mathrm{p}<0.1$. The standard errors are the values in the parentheses. Prob (Fstatistic) showing the overall significant predicative capacity of the model. 
Table VIII. Maximum Likelihood Estimates of Cobb-Douglas Stochastic Frontier Production Model

\begin{tabular}{lcc} 
Variable & Parameter & Coefficient \\
\hline Constant & $\beta_{0}$ & $-178.811^{* * *}(0.986)$ \\
Growers' Field & $\beta_{1}$ & $-0.106^{* *}(0.002)$ \\
Inland Logistics outside the UK & $\beta_{2}$ & $-152.467 * * *(0.734)$ \\
Transportation & $\beta_{3}$ & $37.569^{* * *}(0.146)$ \\
Sales and Distribution & $\beta_{3}$ & $114.974 * * *(0.684)$ \\
Sigma-Squared & $\Sigma$ & $4.339(3.659)$ \\
Gamma & $\Gamma$ & $1.000^{* * *}(0)$ \\
Log likelihood function & & -685.146 \\
LR test of the one-sided error & & 1618.042 \\
Notes: $* * * \mathrm{p}<0.01, * * \mathrm{p}<0.05$ and $* \mathrm{p}<0.1$. The standard errors are the values in the parentheses.
\end{tabular}




\section{Key factors of Carbon footprint in the UK food supply chains: A new perspective of life cycle assessment}

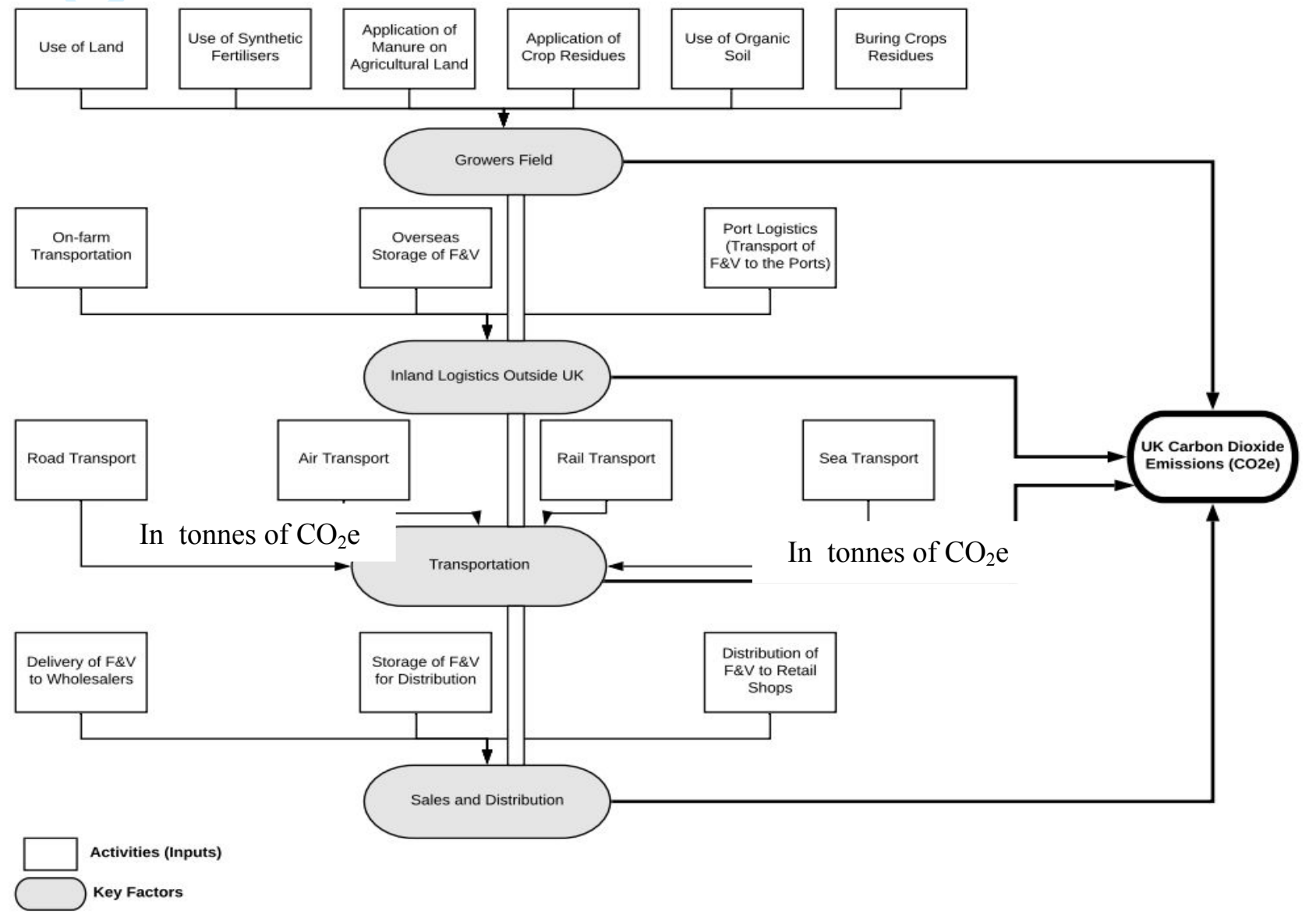

Figure 1. A conceptual framework of $\mathrm{CO}_{2} \mathrm{e}$ in the UK FSC

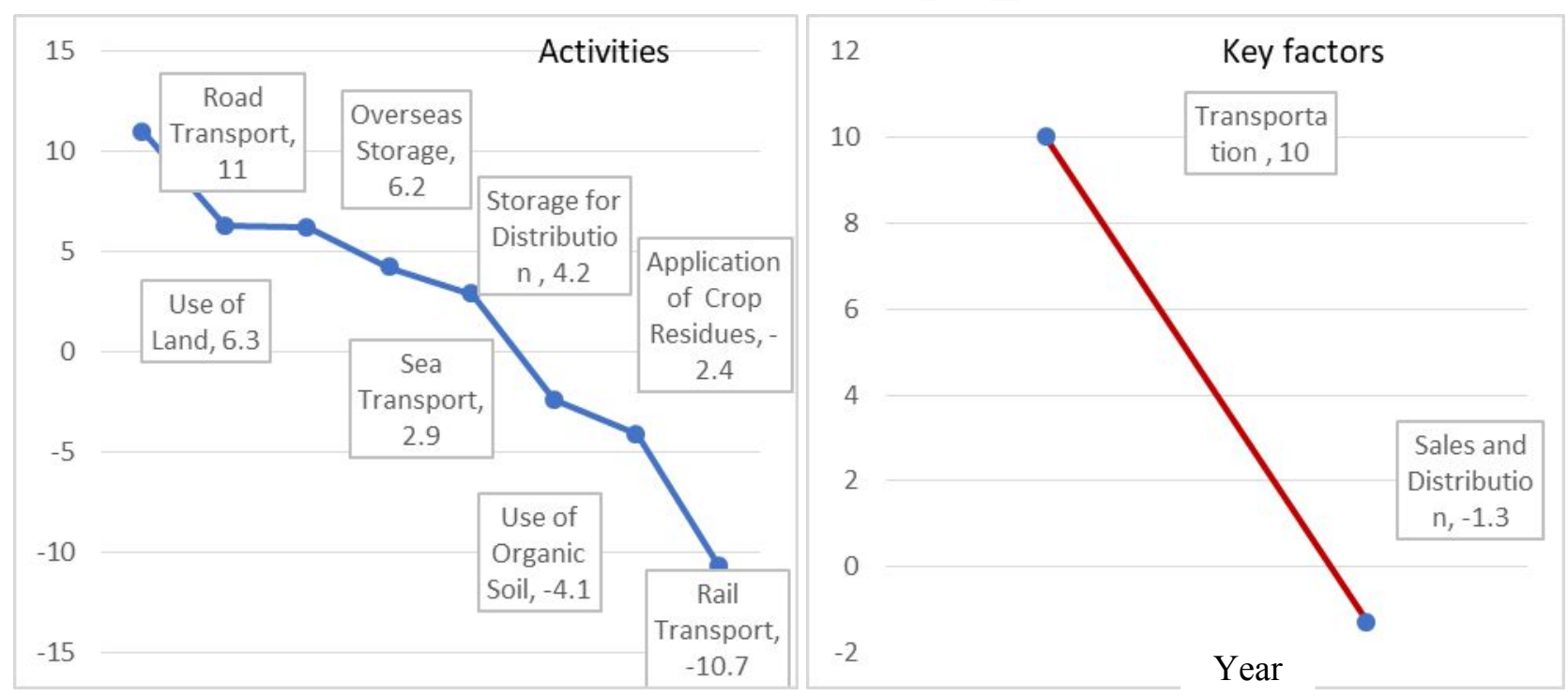

Figure 2. Ranking of significant inputs (activities) and key factors that contribute to $\mathrm{CO}_{2}$ emissions in UK food supply chains. 